\title{
MITIGATION OF GROUND VIBRATIONS BY CIRCULAR ARRAYS OF RIGID BLOCKS
}

\author{
Lars V. Andersen ${ }^{1}$, Andrew T. Peplow ${ }^{2}$, and Peter Persson ${ }^{3}$ \\ ${ }^{1}$ Department of Engineering, Aarhus University \\ Inge Lehmanns Gade 10, DK-8000 Aarhus C, Denmark \\ e-mail: lva@eng.au.dk \\ ${ }^{2}$ Department of Natural Sciences and Public Health, Zayed University \\ P.O. Box 144534, Abu Dhabi, United Arab Emirates \\ e-mail: andrew.peplow@zu.ac.ae \\ ${ }^{3}$ Department of Construction Sciences, Lund University \\ P.O. Box 118, SE-221 00 Lund, Sweden \\ e-mail: peter.persson@construction.lth.se
}

\begin{abstract}
Pile driving and other activities in the built environment cause ground vibration at low frequencies. This may result in annoyance to people as well as damage to civil structures. It is known that masses added on the ground surface can have an impact on the vibration levels in the surrounding environment. Hence, employing a semi-analytical model for rigid blocks on the surface of a layered ground, this paper investigates whether circular arrays of such blocks can be used as a means of vibration mitigation. The frequency range 0-80 $\mathrm{Hz}$ is considered, since this is relevant to whole-body vibrations of humans as well as the fundamental modes of resonance in building elements, e.g., floors and walls. Two different soil profiles are analysed: a soft dry sand layer over a till half-space and a soft wet clay layer over a lime half-space. Further, three configurations of the block arrays are taken into consideration, and for the first soil profile also the height of the blocks is varied to test its influence on the insertion loss in a zone 20-40 $m$ away from the source. The aim is to quantify the overall insertion loss that can be expected using the proposed methodology. Further, the variation in insertion loss caused by changes in the block array configuration is examined.
\end{abstract}

Keywords: Soil, Wave Propagation, Layered Half-Space, Insertion Loss, Wave Impedance. 


\section{INTRODUCTION}

Ground vibrations from traffic or construction work may cause damage to structures. They may as well cause annoyance to inhabitants in urban environments and have an impact on their health. To reduce the problems associated with ground vibrations, several ideas have been proposed for mitigation. This includes trenches and barriers as well as embedded wave-impeding blocks (WIBs) or masses placed on the ground surface. These can be placed in front of a vibration source to prevent vibrations from spreading to the surroundings, or they can be placed in front of a receiver to protect it, or a combination can be used. In any case, the idea is to insert one or more obstacles within the wave propagation path that will redirect, reflect or absorb the waves.

The literature reports several studies of single blocks or barriers [1, 2, 3] as well as, for example, double sheet pile walls $[4,5]$. Especially, the idea of using blocks placed on the ground surface for mitigation of ground vibrations was proposed already in the 1970s by Warburton et al. [7, 8]. Later, Peplow et al. [8] proposed the inclusion of WIBs in the ground, and this concept was validated experimentally by Masoumi et al. [9].

To improve the solution that can be achieved with a single barrier or block, arrays of such barriers and blocks can be introduced. The idea of using structural periodicity to mitigate wave propagation was originally proposed by Mead [10] who analysed a periodically supported beam. Recently, Van et al. [11] developed a methodology to design a one-dimensional wave barrier by topology optimization of a one-dimensional medium. More relevant for the present problem of ground vibration, Persson et al. [12] studied the effect of having repeated hills and/or valleys, and Andersen [13] analysed the effect of linear arrays of rigid blocks embedded in the ground using a two-dimensional model of a periodic structure. This work was extended to three-dimensional analysis of nearly-periodic structures $[14,15,16]$. Furthermore, Peplow et al. $[17,18]$ established simplified modelling approach to analysis of linear arrays of blocks placed on the ground surface. As a common finding of the reported research, periodic inclusions of blocks or other inhomogeneities have an effect on the ground vibrations and may, if designed properly, produce band gaps with (almost) no wave propagation.

As an alternative to the linear barriers or arrays of masses, typically considered, the present paper proposes the use of circular arrays of rigid blocks. Such arrays can be placed, for example, around a pile during driving or around a machine foundation - or it can be placed around a building to partially prevent vibration from reaching it. Only the first scenario is analysed in the paper, using a semi-analytical model of a layered viscoelastic half-space to represent the ground. Rigid blocks are placed on the ground surface in concentric circles surrounding the source point with the aim of reducing the vibration level in a shielded zone $20 \mathrm{~m}$ to $40 \mathrm{~m}$ from the centre of the source. A parameter study is performed regarding the number of circles, the number of blocks in each circle, and the height of the blocks. In any case, the blocks have a footprint of $1 \mathrm{~m}$ by $2 \mathrm{~m}$. It is deemed realistic that such blocks could be produced on a given site, for example, by filling in steel containers or construction-waste bags with soil that can be excavated locally. Thus, it is not necessary to place blocks made, for example, of reinforced concrete that may be difficult and expensive to produce at or move to the site.

In Section 2, the computational model is described. This includes a description of the semianalytical model of the ground and the rigid blocks as well as definition of the various array configurations. Sections 3 and 4 present two case studies. In Case 1, a soft dry sand layer over a till half-space is considered, whereas Case 2 concerns a soft wet clay layer over a lime halfspace. These strata are considered to be representative for soil conditions that could typically cause problems with ground vibrations in the environment surrounding a construction site. Finally, Section 5 lists the main conclusions of the paper. 


\section{COMPUTATIONAL MODEL FOR THE SOIL AND BLOCKS}

\subsection{Model of a layered ground}

The soil is modelled as a linear viscoelastic solid half-space with surface at $x_{3}=0$. In the time domain and using Cartesian coordinates, the displacement response $u_{i}\left(x_{1}, x_{2}, t\right)$ at time $t$ and position $\left(x_{1}, x_{2}\right)$ on the ground surface to a surface traction time series $p_{j}\left(y_{1}, y_{2}, \tau\right)$ acting at the position $\left(y_{1}, y_{2}\right)$ can be found as

$$
u_{i}\left(x_{1}, x_{2}, t\right)=\int_{-\infty}^{\infty} \int_{-\infty}^{\infty} \int_{-\infty}^{t} g_{i j}\left(x_{1}-y_{1}, x_{2}-y_{2}, t-\tau\right) p_{j}\left(y_{1}, y_{2}, \tau\right) \mathrm{d} \tau \mathrm{d} y_{1} \mathrm{~d} y_{2},
$$

where $g_{i j}\left(x_{1}-y_{1}, x_{2}-y_{2}, t-\tau\right)$ is the Green's function for the half-space. This formulation assumes invariance of the Green's function to temporal and spatial translation. The latter requires that the half-space is homogenous in the $x_{1}$ and $x_{2}$ directions, which in turn requires that any layers are horizontal. However, even with these constraints, a general analytical expression for the Green's function cannot be established in the time-space domain. Instead, a semi-analytical solution can be obtained by first solving the problem in frequency-horizontal wavenumber domain. Thus, by a triple Fourier transformation, Eq. (1) is reformulated into

$$
\bar{U}_{i}\left(k_{1}, k_{2}, \omega\right)=\bar{G}_{i j}\left(k_{1}, k_{2}, \omega\right) \bar{P}_{j}\left(k_{1}, k_{2}, \omega\right),
$$

where $\bar{U}_{i}\left(k_{1}, k_{2}, \omega\right)$ is the triple Fourier transform of $u_{i}\left(x_{1}, x_{2}, t\right), \bar{P}_{j}\left(k_{1}, k_{2}, \omega\right)$ is the triple Fourier transform of $p_{j}\left(y_{1}, y_{2}, \tau\right)$, and $\bar{G}_{i j}\left(k_{1}, k_{2}, \omega\right)$ is the triple Fourier transform of $g_{i j}\left(x_{1}, x_{2}, t\right)$. Unlike $g_{i j}\left(x_{1}, x_{2}, t\right)$, a closed-form solution exists for $\bar{G}_{i j}\left(k_{1}, k_{2}, \omega\right)$ in the case of a horizontally layered linear viscoelastic half-space, as first proposed by Thomson [19] and Haskell [20], and as further explained in the work by Andersen and Clausen [21]. For a given combination of wavenumbers and angular frequency, a transfer matrix for a single layer can be determined in closed form, and the transfer matrices for all layers are then multiplied in order to obtain a transfer matrix for the layered half-space. This can finally be rearranged into a Green's function tensor relating the surface displacement to the surface traction.

The computational strategy is to discretize the problem into a number of discrete angular frequencies $\omega_{n}, n=1,2, \ldots, N_{\omega}$. For each frequency, $\bar{G}_{i j}\left(k_{1}, k_{2}, \omega_{n}\right)$ and $\bar{P}_{j}\left(k_{1}, k_{2}, \omega_{n}\right)$ are evaluated at a number of discrete wavenumbers. Next, double inverse discrete Fourier transformation is performed with respect to the horizontal wavenumbers. That brings the solution back into frequency-space domain. Hence, for a given frequency, the displacement $U_{i}\left(x_{1}, x_{2}, \omega\right)$ at any point on the ground surface due to the traction $P_{j}\left(y_{1}, y_{2}, \omega\right)$ at any point on the surface can be found. As pointed out by Andersen and Clausen [21], rotational symmetry of the load can be utilized to speed up the calculations. Further, inverse discrete Fourier transformation can be used to obtain the time-domain solution. However, the present analyses concern the frequency domain with focus on the range $0-80 \mathrm{~Hz}$ that is relevant to whole-body vibration as well as the first modes of resonance in typical building structures and soil profiles.

It is noted that rate-independent material dissipation is assumed in the semi-analytical model of the ground. Hence, hysteretic damping, represented by the loss factor $\eta$, is employed. For each layer of soil, the material properties are further specified in terms of the shear modulus $G$, Poisson's ratio $v$, and the mass density $\rho$.

As an example, Figure 1 shows the steady state ground displacement in a model of a layered soil with $3 \mathrm{~m}$ deep soft dry sand overlying a till half-space. Details on the material properties can be found in Section 3. The load is applied as a uniformly distributed vertical traction over a circular area with a radius of $1 \mathrm{~m}$, and the displacements are plotted at the frequencies $25 \mathrm{~Hz}$ and $30 \mathrm{~Hz}$, respectively, for the zone up to $40 \mathrm{~m}$ away from the centre of the load. 
a)

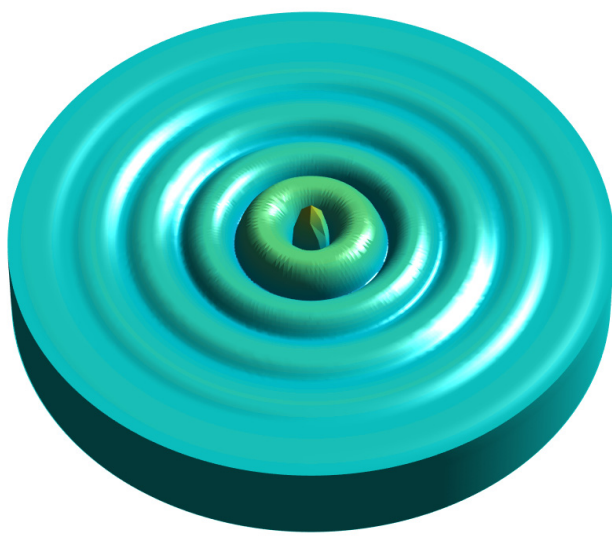

b)

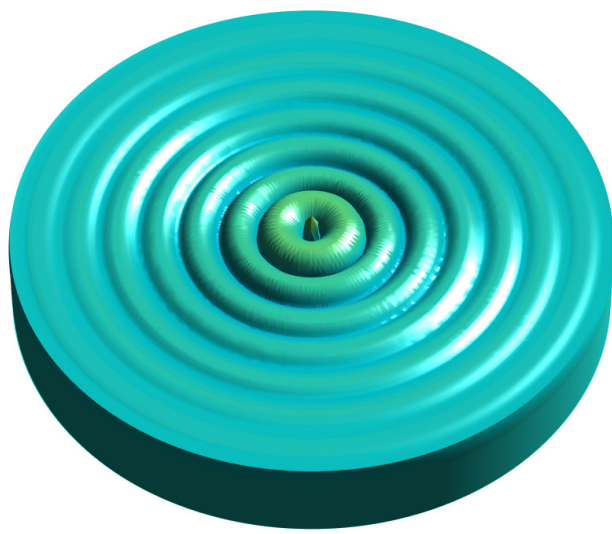

Figure 1: Snapshots of the steady state ground displacement response to a harmonic vertical load applied uniformly over a circular area with radius $1 \mathrm{~m}$ : a) Green field at $25 \mathrm{~Hz}$; b) green field at $30 \mathrm{~Hz}$. The radius of the model is $40 \mathrm{~m}$ and the depth of the model is $12 \mathrm{~m}$.

\subsection{Dynamic soil-structure interaction for an array of rigid blocks}

To model the dynamic soil-structure interaction (SSI) for $N_{B}$ rigid blocks placed on the ground surface, the interface between each block and the soil is discretized into $N_{s s i}$ points. In the present analyses, rectangular blocks are considered with 6 points in one direction and 12 points in the other direction, i.e. $N_{s s i}=72$. Hence, the total number of soil-structure interaction points will be $N_{S S I}=N_{S S i} N_{B}=72 N_{B}$. At each of the SSI points, traction is assumed to be distributed on a small area with rotational symmetry around the point. With reference [21], a socalled "bell-shaped" traction is applied, i.e. a double Gaussian distribution in the $\left(x_{1}, x_{2}\right)$ plane. Further, load is applied at a source point, adding another three degrees of freedom (d.o.f.) to the problem, i.e. the discretized ground surface as $3+3 N_{B} N_{s s i}$ displacement d.o.f.. A global flexibility matrix $\mathbf{C}_{S S I}\left(\omega_{n}\right)$ can now be established, employing the Green's function $G_{i j}\left(x_{1}-\right.$ $\left.y_{1}, x_{2}-y_{2}, \omega_{n}\right)$ which relates $U_{i}\left(x_{1}, x_{2}, \omega_{n}\right)$ to $P_{j}\left(y_{1}, y_{2}, \omega_{n}\right)$. Each of the rigid blocks has six d.o.f., i.e. a total of $6 N_{B}$ rigid-body modes can be identified for the blocks. In addition to this, the three d.o.f. for the source point must be considered. Thus, one by one, a unit displacement or rotation is prescribed for each of the $6 N_{B}+3$ d.o.f. while fixing the remaining d.o.f. for the blocks and the load. The displacement components are determined for each of the $N_{s s i}$ points of the local interface between the soil and the block with prescribed unit rigid-body motion. This provides the matrix $\mathbf{U}_{0}$, where each column defines one rigid-body mode of a block or the displacement of the source point in one direction. The magnitude of the traction at each SSI point due to each unit displacement or rotation can be found as the solution to $\mathbf{C}_{S S I}\left(\omega_{n}\right) \mathbf{P}_{0}\left(\omega_{n}\right)=\mathbf{U}_{0}$. Finally, for each discrete frequency, a stiffness matrix for the SSI problem can then be expressed as $\mathbf{D}_{S S I}\left(\omega_{n}\right)=\mathbf{U}_{0}^{T} \mathbf{P}_{0}\left(\omega_{n}\right)$. This matrix will have the dimensions $\left(\left(6 N_{B}+3\right) \times\left(6 N_{B}+3\right)\right)$.

Once, the $6 N_{B}+3$ rigid-body translations and rotations of the blocks and source point have been determined for a given load, the displacement at a number of discrete points on the ground surface can be determined by using the Green's function. In the present analyses, a circular zone with radius $40 \mathrm{~m}$ is considered, as already discussed in the previous subsection. The discrete points are organized in a regular pattern with a $1.0 \mathrm{~m}$ distance in the radial direction and approximately $1.0 \mathrm{~m}$ distance in the azimuthal direction. More precisely, 6 points are placed in the circle with radius $1 \mathrm{~m}, 12$ points are placed in the circle with radius $2 \mathrm{~m}$, and so on. This provides a total of 4921 observation points on the ground surface. 


\subsection{Block array configurations}

In order to assess the potential of using circular block arrays to mitigate ground vibration from a single source on a layered ground, three different overall configurations of the blocks will be considered. In any case, the blocks are placed on the ground surface in one, two or three concentric rings with the radii $4 \mathrm{~m}, 8 \mathrm{~m}$ and $12 \mathrm{~m}$, respectively. The radii refer to the distance between the centre of the loaded circular area and the midpoints of the SSI interfaces between the individual blocks and the soil. The three configurations are:

a) "Stonehenge" configurations with 6,12 and 24 blocks in Rings 1, 2 and 3, respectively, cf. Figure $2 \mathrm{a}$. The blocks in the inner Ring 1 have the footprint $2 \mathrm{~m} \times 1 \mathrm{~m}$ with the longer side placed tangentially to the perimeter of the circle. The side lengths of the blocks in Rings 2 and 3 are scaled by a factor of $0.5^{1 / 3}$ and $0.5^{2 / 3}$, respectively, and the height of the blocks are scaled by the same factors. Hence, the volume (and hence the mass) of the blocks in Ring 2 will be one-half compared to that of the blocks in Ring 1, whereas the volume (and mass) of the blocks in Ring 3 will be scaled by a factor 0.25 . Given that each ring contains twice the number of blocks, the total mass of the blocks in each ring is therefore the same.

a)
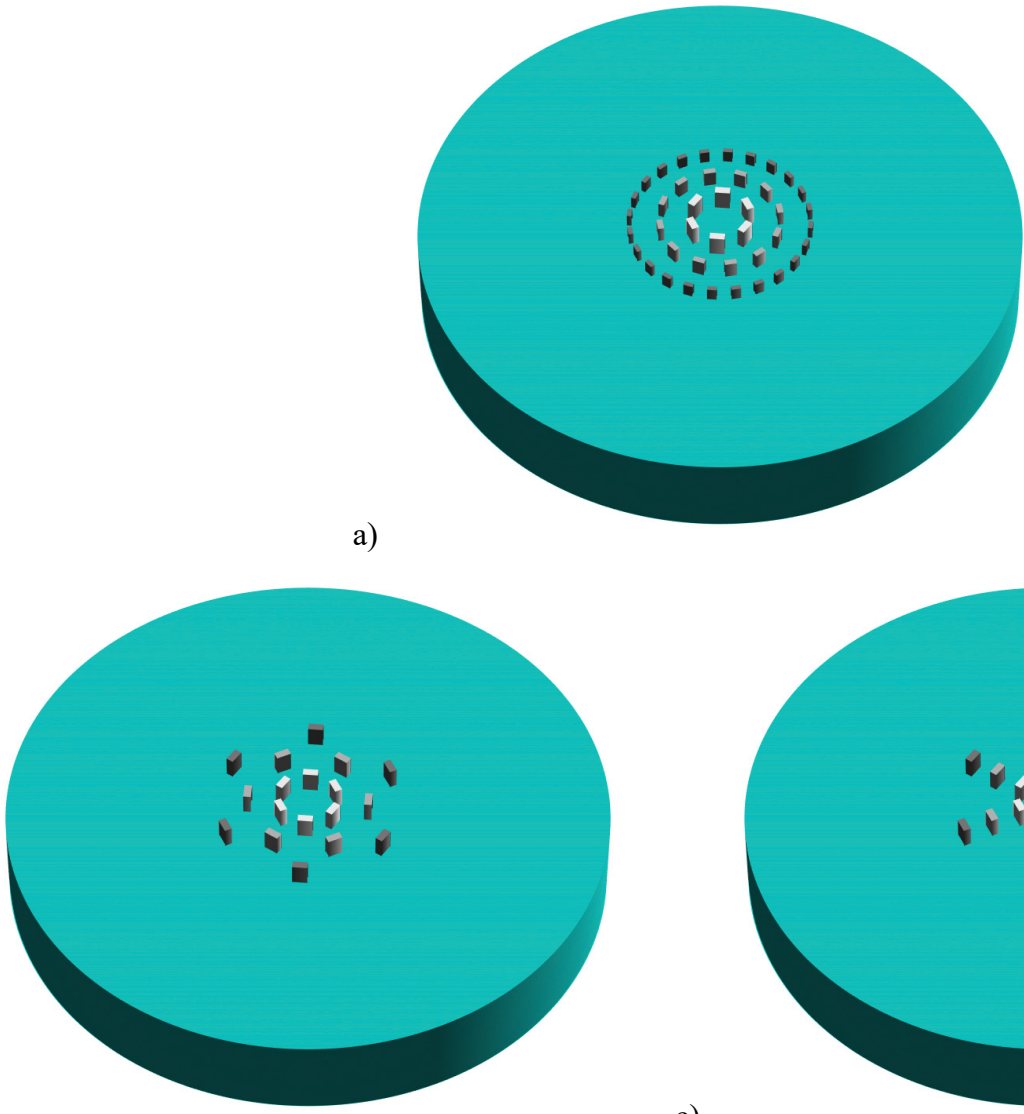

c)

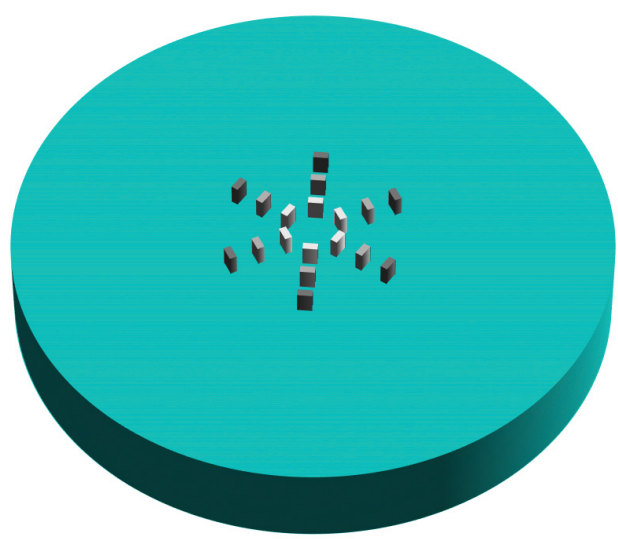

Figure 2: Three configurations of rigid blocks on the ground surface: a) "Stonehenge" with 6, 12 and 24 blocks in Rings 1, 2 and 3, respectively; b) "turned rings" with six identical blocks in each ring and Ring 2 turned $30^{\circ}$; c) six "linear arrays" with three blocks in each array. The total mass of all blocks in each ring is identical in all configurations. The radius of the rings are $4 \mathrm{~m}, 8 \mathrm{~m}$ and $12 \mathrm{~m}$, respectively, and the radius of the model is $40 \mathrm{~m}$. 
b) "Turned rings" with six blocks in each ring and with Ring 2 turned by $30^{\circ}$ around a vertical axis through the load centre relative to Rings 1 and 3 , cf. Figure $2 \mathrm{~b}$. Thus, when all rings are present, the middle ring "closes the gaps" between the blocks in the inner and outer rings. In this configuration, the blocks are identical, all having the footprint $2 \mathrm{~m} \times 1 \mathrm{~m}$, again with the longer side placed tangentially to the perimeter of the circle. Given that six blocks are present in each ring, the total mass of the blocks in each ring is therefore again the same.

c) "Linear arrays" with one, two or three blocks lined up along six radii, cf. Figure 2c. Except for the relative orientation of Ring 2, this configuration is identical to the "turned rings".

The blocks are rigid and have a mass density of $2000 \mathrm{~kg} / \mathrm{m}^{3}$. The height of all blocks (in the inner Ring 1 for the "Stonehenge" configuration" and in all rings for the other configurations) is either $1 \mathrm{~m}, 2 \mathrm{~m}$ or $3 \mathrm{~m}$. As indicated above, the blocks in Rings 2 and 3 in the "Stonehenge" configuration will be downscaled to provide the same total mass in each ring.

Figure 3 shows example results for the "Stonehenge" configuration with three rings of blocks placed on a soft dry sand layer over a till half-space (the soil properties are given in Section 3). These results should be compared with the green-field response shown in Figure 1. Clearly, for the present case, the "Stonehenge" provides excellent mitigation of ground vibrations in the surrounding environment at the frequency $25 \mathrm{~Hz}$, whereas the effect at $30 \mathrm{~Hz}$ is limited.

a)

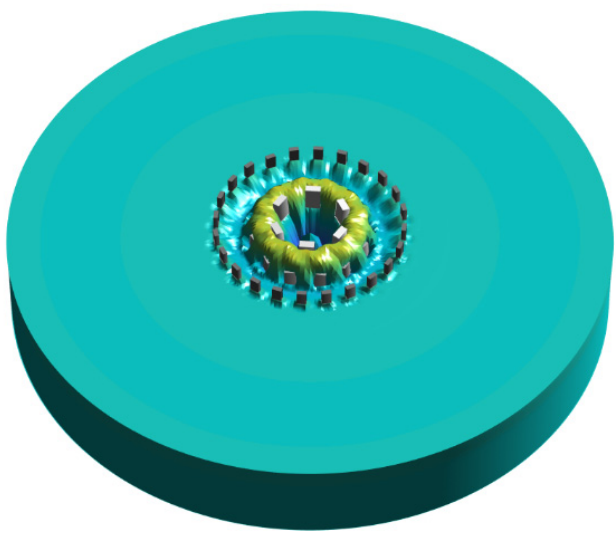

b)

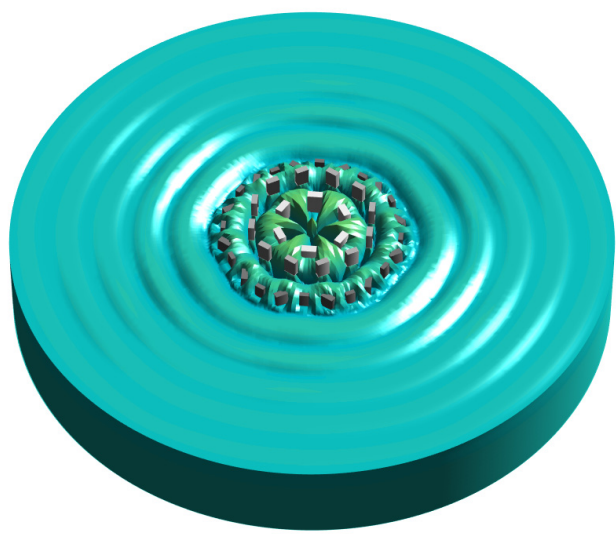

Figure 3: Snapshots of the steady state ground displacement response to a harmonic vertical load applied uniformly over a circular area with radius $1 \mathrm{~m}$ : a) "Stonehenge" at $25 \mathrm{~Hz}$; b) "Stonehenge" at $30 \mathrm{~Hz}$. The radius of the model is $40 \mathrm{~m}$ and the depth of the model is $12 \mathrm{~m}$.

\subsection{Calculation of insertion loss and transmission loss in protected zone}

To quantify the effect of block arrays with different configurations on the ground vibration level in the surrounding environment, the insertion loss (IL) is calculated. For a given position $\left(x_{1}, x_{2}\right)$ and angular frequency $\omega$, the IL is determined as the difference in $\mathrm{dB}$ in the vibration levels before and after insertion of the blocks, defining a reduction in vibration level as a positive insertion loss. For displacement component $i$ and block array configuration $j$,

$$
I L_{i}^{j}\left(x_{1}, x_{2}, \omega\right)=20 \log _{10}\left(\left|U_{i}^{0}\left(x_{1}, x_{2}, \omega\right)\right|\right)-20 \log _{10}\left(\left|U_{i}^{j}\left(x_{1}, x_{2}, \omega\right)\right|\right),
$$

where $U_{i}^{j}\left(x_{1}, x_{2}, \omega\right)$ is the displacement amplitude after insertion of the block array, and $U_{i}^{0}\left(x_{1}, x_{2}, \omega\right)$ is the reference displacement amplitude before insertion of the block array, i.e. the vibration level in the green field. The present analyses consider vertical vibrations caused by a unit-magnitude vertical load applied uniformly over a circular area with radius $1 \mathrm{~m}$. Hence, $I L_{3}^{j}\left(x_{1}, x_{2}, \omega\right)$ is calculated at the 4921 observation points on the ground surface. 
A high value for IL is advantageous. However, array configurations that provide high IL in frequency ranges with low vibration levels, but low IL in frequency ranges with high vibration levels, are not effective solutions. Hence, to assess the quality of an array, the reference level $(\mathrm{RL})$ for vibrations at a given observation point is important. The present analyses employ the definition:

$$
R L_{i}\left(x_{1}, x_{2}, \omega\right)=20 \log _{10}\left(\left|U_{i}^{0}\left(x_{1}, x_{2}, \omega\right)\right|\right)-20 \log _{10}\left(U_{\text {ref }}\right),
$$

where $U_{i}^{0}\left(x_{1}, x_{2}, \omega\right)$ is the displacement amplitude in the greenfield when a unit-magnitude $(1 \mathrm{~N})$ vertical load is applied, and $U_{\text {ref }}=1 \mathrm{pm}$. Again, the vertical vibration level is in focus; hence, $R L_{3}\left(x_{1}, x_{2}, \omega\right)$ is evaluated for the observation points. It should be noted that the present definition of the RL corresponds to a transfer function for the layered ground. Thus, it contains no information about the frequency content of a source - it only provides information about the capacity of the ground to transfer vibration from a position at the surface to another.

In the following sections, the IL and RL will be determined for two different stratifications of the soil and for the various configurations of the block arrays described in the previous subsection. In order to provide single-value measures of the IL and RL at a given frequency, the mean values of $I L_{3}^{j}\left(x_{1}, x_{2}, \omega\right)$ and $R L_{3}\left(x_{1}, x_{2}, \omega\right)$ are determined for the donut-shaped zone, coined here as the "shielded zone" bounded by the two circles with radii $20 \mathrm{~m}$ and $40 \mathrm{~m}$, respectively. Further, the $10 \%$ and $90 \%$ quantiles are calculated in order to quantify the variation of the quantities within the shielded zone.

\section{CASE 1: A SOFT DRY SAND LAYER OVER A HALF-SPACE OF TILL}

The first case concerns a $3 \mathrm{~m}$ deep soft dry sand layer overlying a half-space of till. Material properties for the two soil layers are listed in Table 1. Three subcases are considered: Case 1.1 with $1 \mathrm{~m}$ high blocks, Case 1.2 with $2 \mathrm{~m}$ high blocks and Case 1.3 with $3 \mathrm{~m}$ high blocks.

\begin{tabular}{llllll}
\hline $\begin{array}{l}\text { Soil layer } \\
\text { (from top) }\end{array}$ & $\begin{array}{l}\text { Shear modulus } \\
G[\mathrm{MPa}]\end{array}$ & $\begin{array}{l}\text { Poisson's ratio } \\
v[-]\end{array}$ & $\begin{array}{l}\text { Mass density } \\
\rho\left[\mathrm{kg} / \mathrm{m}^{3}\right]\end{array}$ & $\begin{array}{l}\text { Loss factor } \\
\eta[\%]\end{array}$ & $\begin{array}{l}\text { Thickness } \\
h[\mathrm{~m}]\end{array}$ \\
\hline Sand, soft, $d r y$ & 35.72 & 0.3330 & 1553 & 4.50 & 3.0 \\
Till (half-space) & 500.0 & 0.3500 & 2100 & 2.00 & $\infty$ \\
\hline
\end{tabular}

Table 1: Soil properties for Case 1.

\subsection{Case 1.1: $1 \mathrm{~m}$ high blocks in three configurations}

Table 2 shows the resonance frequencies of the blocks in Rings 1, 2 and 3 for the various configurations of the $1 \mathrm{~m}$ high blocks in Case 1.1. The resonance frequencies are calculated from the static stiffness of the ground and the inertia of the blocks. With reference to Subsection 2.3, subcases a, b and c refer to the "Stonehenge", "turned ring" and "linear array" configurations, respectively. Only the vertical rigid-body translation (or heave mode) and the rotation around the longer main axis of the SSI interface (or pitch mode) of the blocks are considered. These modes are deemed to be important regarding the interaction with the surface wave propagating away from the source.

As a first observation, the resonance frequencies are all in the considered frequency range $0-80 \mathrm{~Hz}$, and the pitch mode has a resonance frequency slightly below that of the heave mode. Further, the smaller blocks in Rings 2 and 3 of the "Stonehenge" configurations (Case 1.1a) have higher resonance frequencies than the larger blocks in Ring 1. This is expected, since the SSI areas are reduced less than the volumes, given that the same scaling is applied in all directions (length, width and height). 
Lars V. Andersen, Andrew T. Peplow and Peter Persson

\begin{tabular}{lllllll}
\hline & \multicolumn{2}{l}{ Blocks in Ring 1 } & \multicolumn{2}{l}{ Blocks in Ring 2 } & \multicolumn{2}{l}{ Blocks in Ring 3 } \\
\cline { 2 - 7 } & Heave & Pitch & Heave & Pitch & Heave & Pitch \\
\hline Case 1.1a & 29.64 & 19.72 & 34.27 & 26.66 & 40.26 & 33.20 \\
Case 1.1b & 29.64 & 19.72 & 29.60 & 22.68 & 29.60 & 19.70 \\
Case 1.1c & 29.64 & 19.72 & 29.60 & 19.70 & 29.60 & 19.70 \\
\hline
\end{tabular}

Table 2: Resonance frequencies (in $\mathrm{Hz}$ ) of blocks in Case 1.1.

Figure 4 shows the mean values of the IL and RL in the shielded zone $(20 \mathrm{~m}$ to $40 \mathrm{~m}$ from the centre of the load) in Case 1.1a for the frequency range $0-80 \mathrm{~Hz}$ and for "Stonehenge" configurations with either 1, 2 or 3 rings. Figure 5 shows the RL (top left quadrants of the subplots) and IL (remaining quadrants of the subplots) on the ground surface at nine selected frequencies. Figure 6 and Figure 7 show similar results for Case 1.1b, the "turned rings", while Figure 8 and Figure 9 show the results for Case 1.1c, the "linear arrays".

Generally, for Case 1, the RL of vibration in the shielded zone is low for frequencies below $10 \mathrm{~Hz}$, and it increases significantly with an increase of the frequency in the range 10-20 Hz. This is due to the presence of a cut-on frequency for wave propagation in the sand layer around $12.5 \mathrm{~Hz}$. Below this frequency, the far-field response is dominated by wave propagation in the much stiffer till half-space, while the soft topsoil only influences the local response near the source. As the frequency is further increased in the range $20-80 \mathrm{~Hz}$, the mean RL in the shielded zone decreases. It should be noted that results are presented for the displacement. Obviously, the frequency dependencies for velocity and acceleration amplitudes are different.

In terms of the mean IL in the shielded zone, the "Stonehenge" and "turned ring" configurations provide similar results. A small peak in the IL is observed around $22 \mathrm{~Hz}$, and the IL is generally high, around $10 \mathrm{~dB}$ in the frequency range $25-40 \mathrm{~Hz}$. A $5 \mathrm{~dB}$ increase of the IL is achieved by insertion of three rings instead of just one ring. However, by a closer inspection, it can be observed that Cases $1.1 \mathrm{a}$ and $1.1 \mathrm{~b}$ are different in terms of the variation of the IL within the shielded zone. For example, at $25 \mathrm{~Hz}$ and $30 \mathrm{~Hz}$ the "Stonehenge" with 2 rings or 3 rings provides IL distributions with a high degree of rotational symmetry cf. Figure 5, whereas the "turned rings" provide more variation in the IL, cf. Figure 7.

The third configuration, the "linear array" provides a result that is different from the two other configurations. Thus, Figure 8 shows a significant IL around $22 \mathrm{~Hz}$, which was not the case for the other configurations. However, around $40 \mathrm{~Hz}$, the IL is low compared to the other configurations of the block array, and there is almost no gain in IL by inclusion of a second or third ring. As an interesting observation in Figure 9, it is noted that the linear arrays do not provide maximum IL in the parts of the shielded zone that lie directly behind the blocks. Due to wave scattering and interference, the IL at some frequencies is 10-15 $\mathrm{dB}$ higher in the gaps between the linear arrays than just behind the linear arrays. 


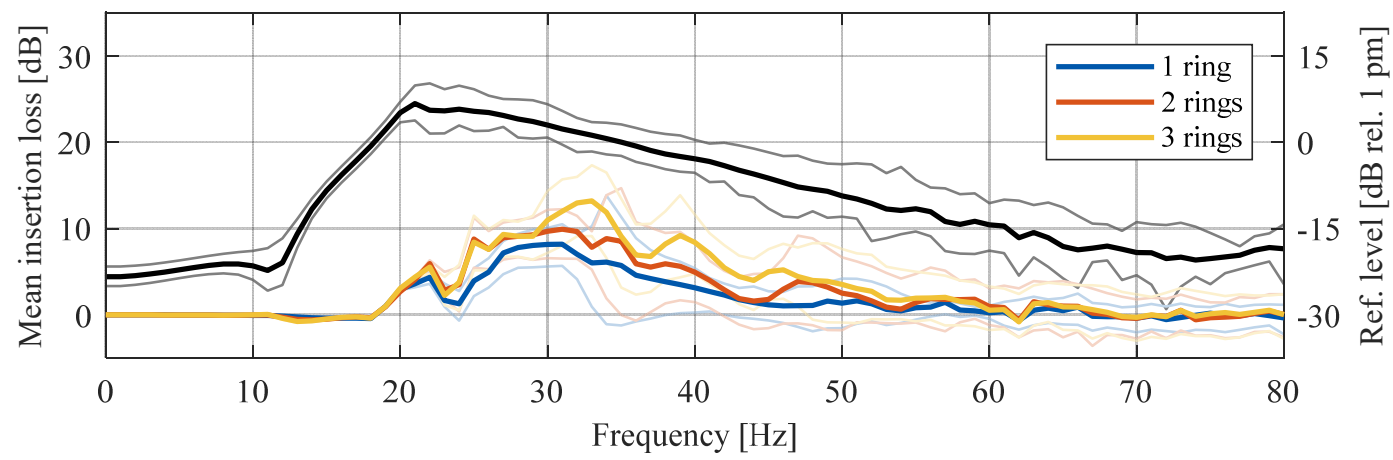

Figure 4: Mean insertion loss in $\mathrm{dB}$ for the donut-shaped zone between $20 \mathrm{~m}$ and $40 \mathrm{~m}$ away from the centre of the loaded area. Case 1.1a: "Stonehenge" with $1 \mathrm{~m}$ high blocks (inner circle) on soft dry sand over till. The black line shows the reference level of vibration. Thin lines show $10 \%$ and $90 \%$ quantiles.
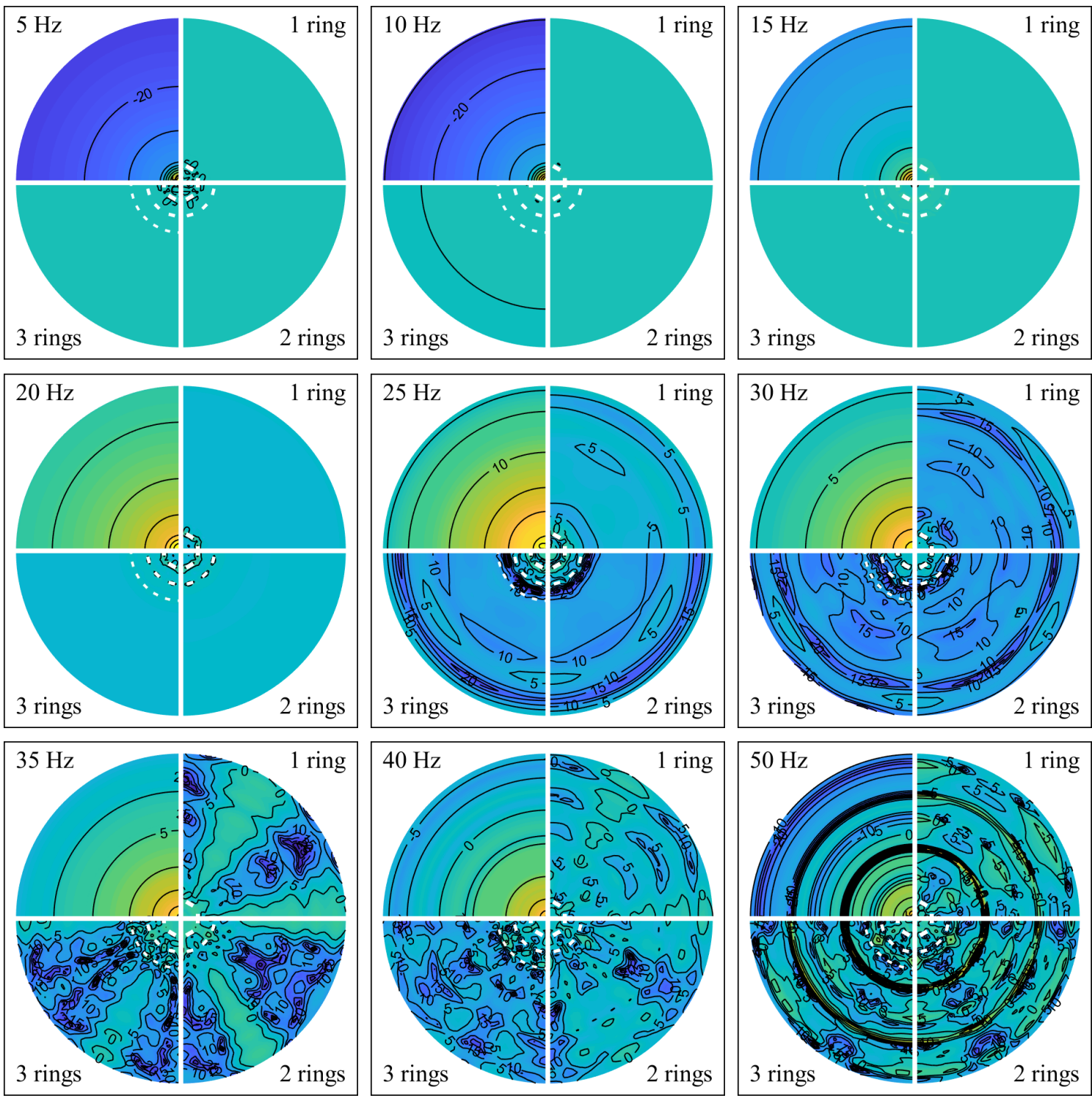

Figure 5: Contours of the reference vibration levels and insertion losses (in $\mathrm{dB}$ ) for Case 1.1a, "Stonehenge" with 1, 2 and 3 rings. Pale yellow/dark blue shades represent unfavourable/favourable values, respectively. 


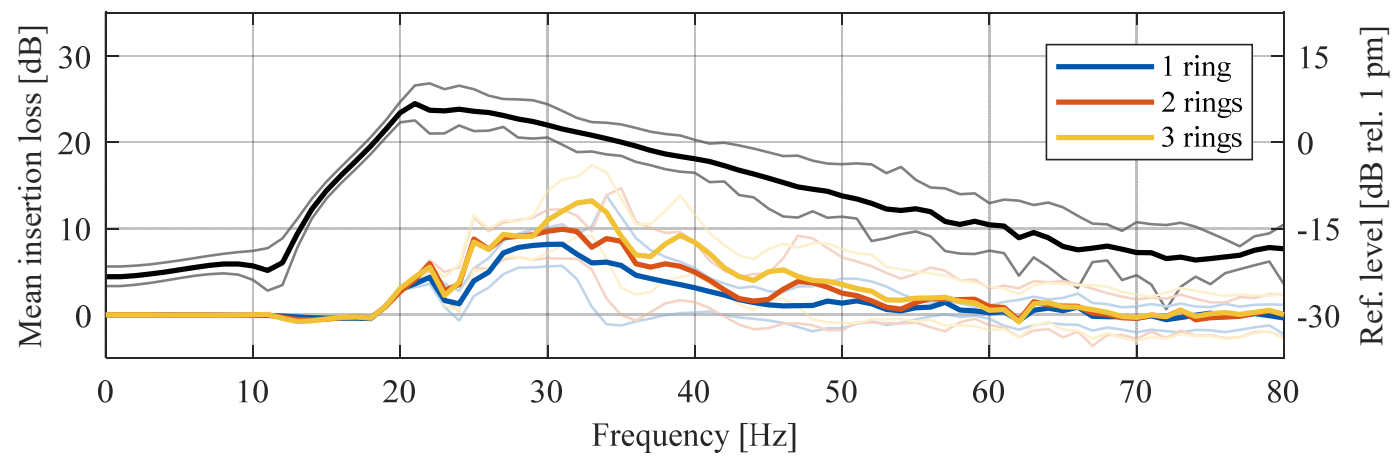

Figure 6: Mean insertion loss in $\mathrm{dB}$ for the donut-shaped zone between $20 \mathrm{~m}$ and $40 \mathrm{~m}$ away from the centre of the loaded area. Case 1.1b: "Turned rings" with $1 \mathrm{~m}$ high blocks (inner circle) on soft dry sand over till. The black line shows the reference level of vibration. Thin lines show $10 \%$ and $90 \%$ quantiles.
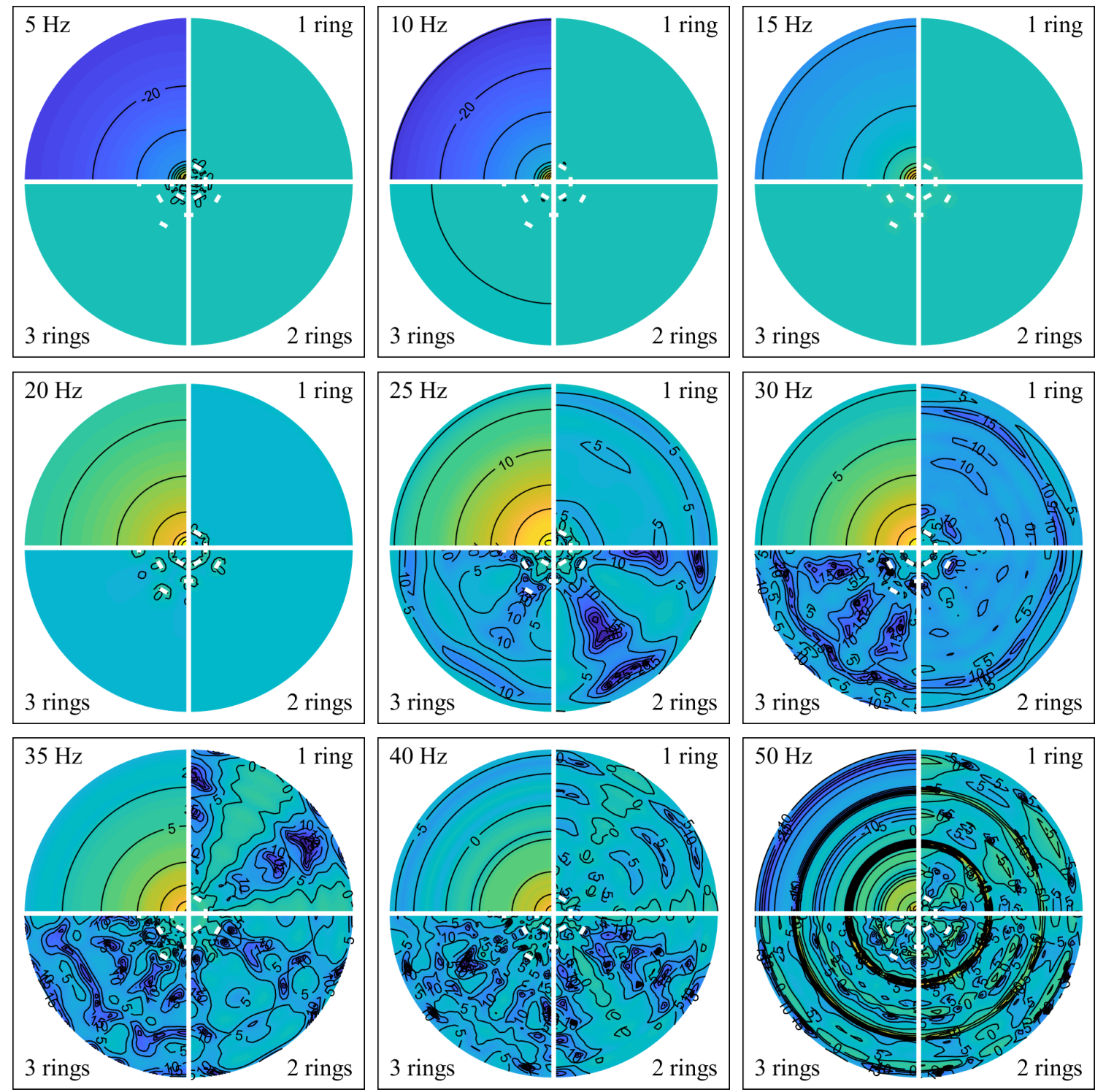

Figure 7: Contours of the reference vibration levels and insertion losses (in $\mathrm{dB}$ ) for Case 1.1b, "turned rings" with 1, 2 and 3 rings. Pale yellow/dark blue shades represent unfavourable/favourable values, respectively. 


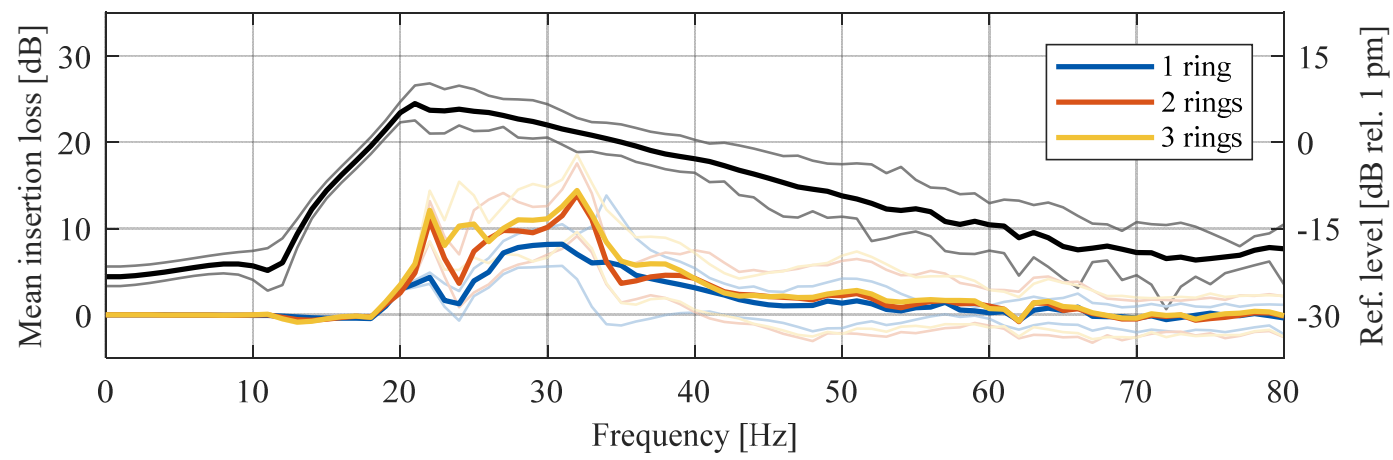

Figure 8: Mean insertion loss in $\mathrm{dB}$ for the donut-shaped zone between $20 \mathrm{~m}$ and $40 \mathrm{~m}$ away from the centre of the loaded area. Case 1.1c: "Linear arrays" with $1 \mathrm{~m}$ high blocks (inner circle) on soft dry sand over till. The black line shows the reference level of vibration. Thin lines show $10 \%$ and $90 \%$ quantiles.
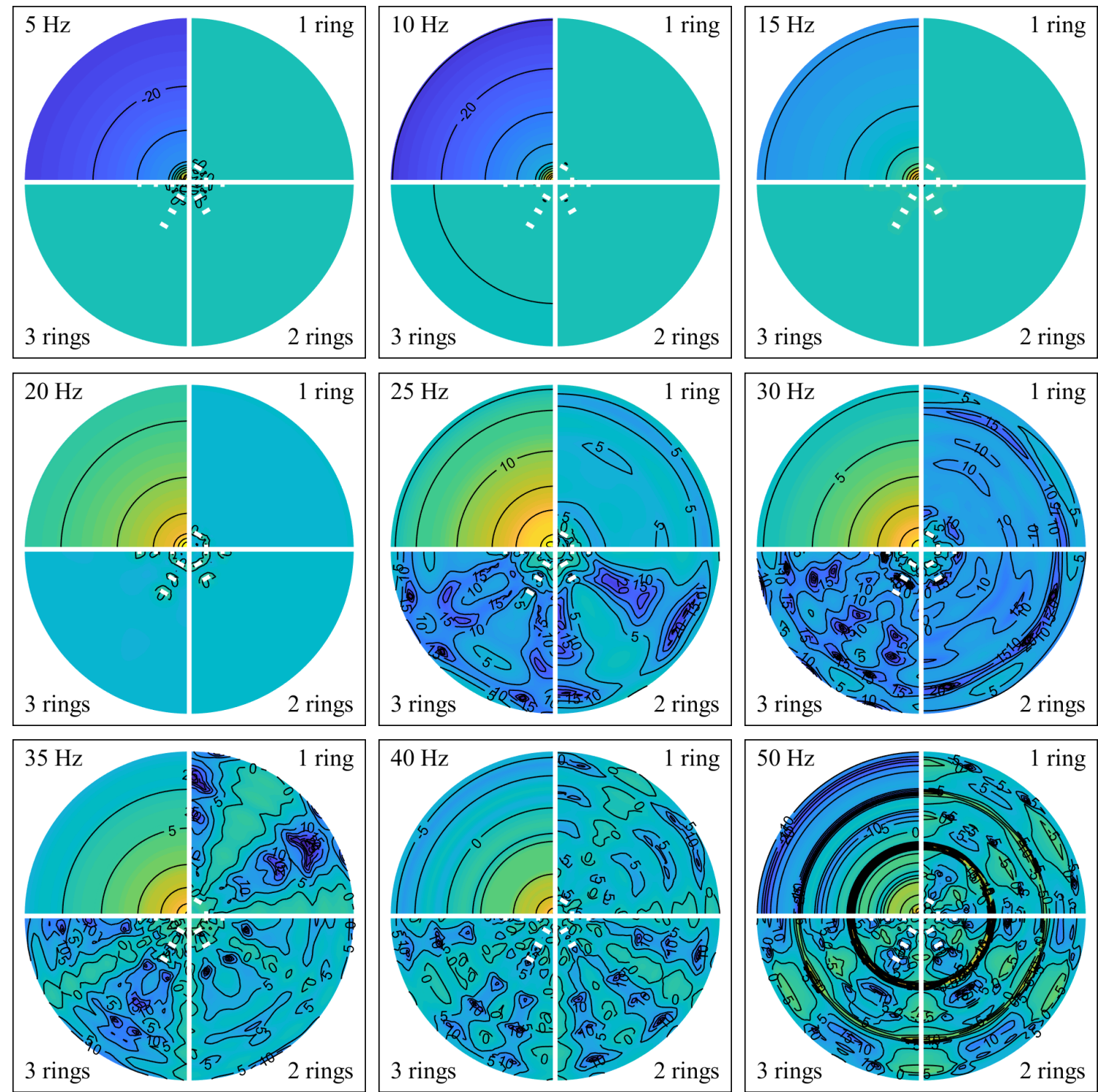

Figure 9: Contours of the reference vibration levels and insertion losses (in $\mathrm{dB}$ ) for Case 1.1c, "linear arrays" with 1, 2 and 3 rings. Pale yellow/dark blue shades represent unfavourable/favourable values, respectively. 


\subsection{Case 1.2: $2 \mathrm{~m}$ high blocks in three configurations}

Table 3 shows the resonance frequencies of the blocks in Rings 1, 2 and 3 for the various configurations of the $2 \mathrm{~m}$ high blocks in Case 1.2. Compared with the resonance frequencies listed in Table 2 (for Case 1.1 with $1 \mathrm{~m}$ high block), the values in Table 3 are considerably lower, especially for the pitch mode. This can be explained by the relatively larger increase of the rotational inertia compared to the increase of the mass. It can be observed that the resonance frequency for the pitch mode is now below the cut-on frequency for wave propagation in the top layer, but the resonance frequencies for the heave mode a closer to the peak of the RL.

\begin{tabular}{lllllll}
\hline & \multicolumn{2}{l}{ Blocks in Ring 1 } & \multicolumn{2}{l}{ Blocks in Ring 2 } & \multicolumn{2}{l}{ Blocks in Ring 3 } \\
\cline { 2 - 6 } & Heave & Pitch & Heave & Pitch & Heave & Pitch \\
\hline Case 1.2a & 20.96 & 7.562 & 24.23 & 9.977 & 28.47 & 12.73 \\
Case 1.2b & 20.96 & 7.562 & 20.93 & 9.128 & 20.93 & 7.554 \\
Case 1.2c & 20.96 & 7.562 & 20.93 & 7.555 & 20.93 & 7.554 \\
\hline
\end{tabular}

Table 3: Resonance frequencies (in Hz) of blocks in Case 1.2.

Figure 10 shows the mean values of the IL and RL in the shielded zone $(20 \mathrm{~m}$ to $40 \mathrm{~m}$ from the centre of the load) in Case $1.2 \mathrm{a}$ for the frequency range $0-80 \mathrm{~Hz}$ and for "Stonehenge" configurations with either 1, 2 or 3 rings. Figure 11 shows the RL (top left quadrants of the subplots) and IL (remaining quadrants of the subplots) on the ground surface at nine selected frequencies. Figure 12 and Figure 13 show similar results for Case 1.2b, the "turned rings", while Figure 14 and Figure 15 show the results for Case 1.2c, the "linear arrays".

Compared to Case 1.1, the general observation is that the $2 \mathrm{~m}$ high blocks provide significantly higher IL than the $1 \mathrm{~m}$ high blocks in the frequency range 17-30 Hz. Especially, a very pronounced peak is present in the mean IL around $18 \mathrm{~Hz}$. The IL at higher frequencies is at the same time slightly reduced. This results from the lower resonance frequencies of the blocks due to the increase of inertia when the blocks become higher.

Little improvement is obtained by including Ring 3 compared to having only two rings. However, for the "Stonehenge" configuration, the IL in the frequency range $28-35 \mathrm{~Hz}$ is increased by about $5 \mathrm{~dB}$ by insertion of Ring 3 . A smaller gain in the IL, about $2-3 \mathrm{~dB}$, is achieved in Case $1.2 \mathrm{~b}$ within the frequency range $23-32 \mathrm{~Hz}$ after insertion of the third ring.

Compared to Cases 1.2b and 1.2c (cf. Figure 12 and Figure 14), the IL is significantly higher in Case 1.2a (cf. Figure 10) for the configurations with two or three rings in the frequency range 23-33 Hz. Here, the "Stonehenge" configuration provides an IL of about $20 \mathrm{~dB}$, which can be considered a very large reduction in the vibration level. Furthermore, inspection of Figure 11 shows that the IL is fairly homogeneous, though with variation between $15 \mathrm{~dB}$ and $30 \mathrm{~dB}$. There are no spots with low IL in the shielded zone. For the IL peak near $20 \mathrm{~Hz}$, an even more uniform distribution of the IL can be observed.

Finally, comparing Cases $1.2 \mathrm{~b}$ and $1.2 \mathrm{c}$ it can be observed that the "linear arrays" with $2 \mathrm{~m}$ high blocks tend to provide higher IL just behind the arrays at $30 \mathrm{~Hz}$, whereas the IL is on average higher for the "turned rings", but with more local variations. This demonstrates that the orientation of the individual rings can be important in the design of the array, when the goal is to protect certain smaller zones, rather than the entire larger zone. 


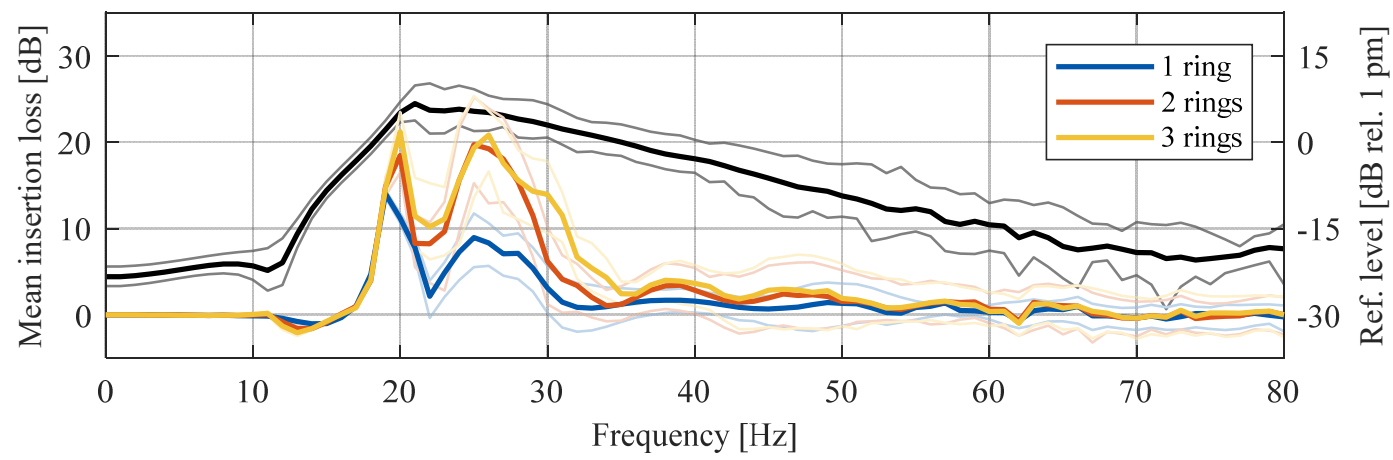

Figure 10: Mean insertion loss in $\mathrm{dB}$ for the donut-shaped zone between $20 \mathrm{~m}$ and $40 \mathrm{~m}$ away from the centre of the loaded area. Case 1.2a: "Stonehenge" with $2 \mathrm{~m}$ high blocks (inner circle) on soft dry sand over till. The black line shows the reference level of vibration. Thin lines show $10 \%$ and $90 \%$ quantiles.
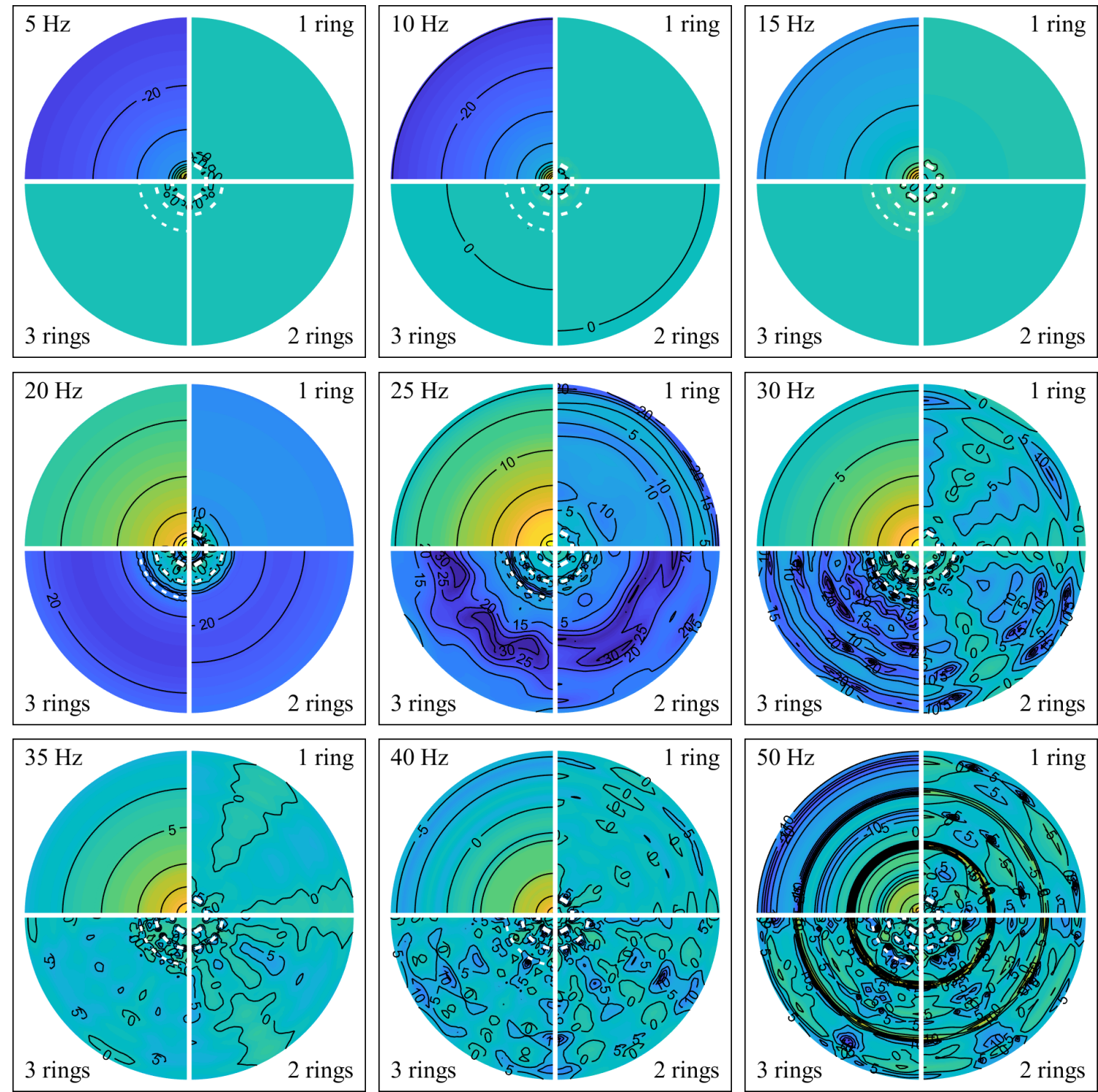

Figure 11: Contours of the reference vibration levels and insertion losses (in $\mathrm{dB}$ ) for Case 1.2a, "Stonehenge" with 1, 2 and 3 rings. Pale yellow/dark blue shades represent unfavourable/favourable values, respectively. 


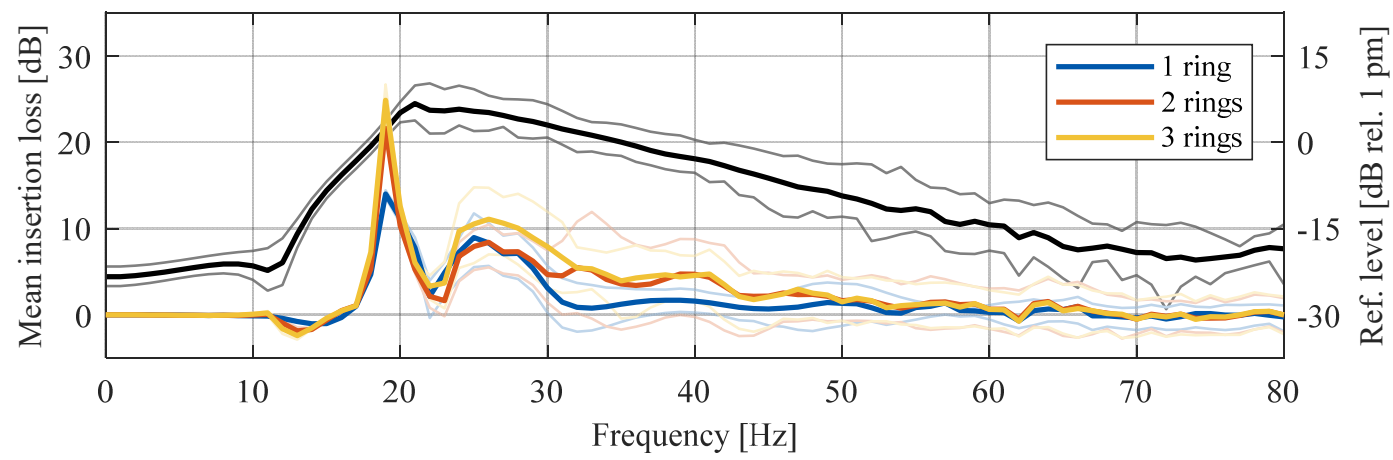

Figure 12: Mean insertion loss in $\mathrm{dB}$ for the donut-shaped zone between $20 \mathrm{~m}$ and $40 \mathrm{~m}$ away from the centre of the loaded area. Case 1.2b: "Turned rings" with $2 \mathrm{~m}$ high blocks (inner circle) on soft dry sand over till. The black line shows the reference level of vibration. Thin lines show $10 \%$ and $90 \%$ quantiles.
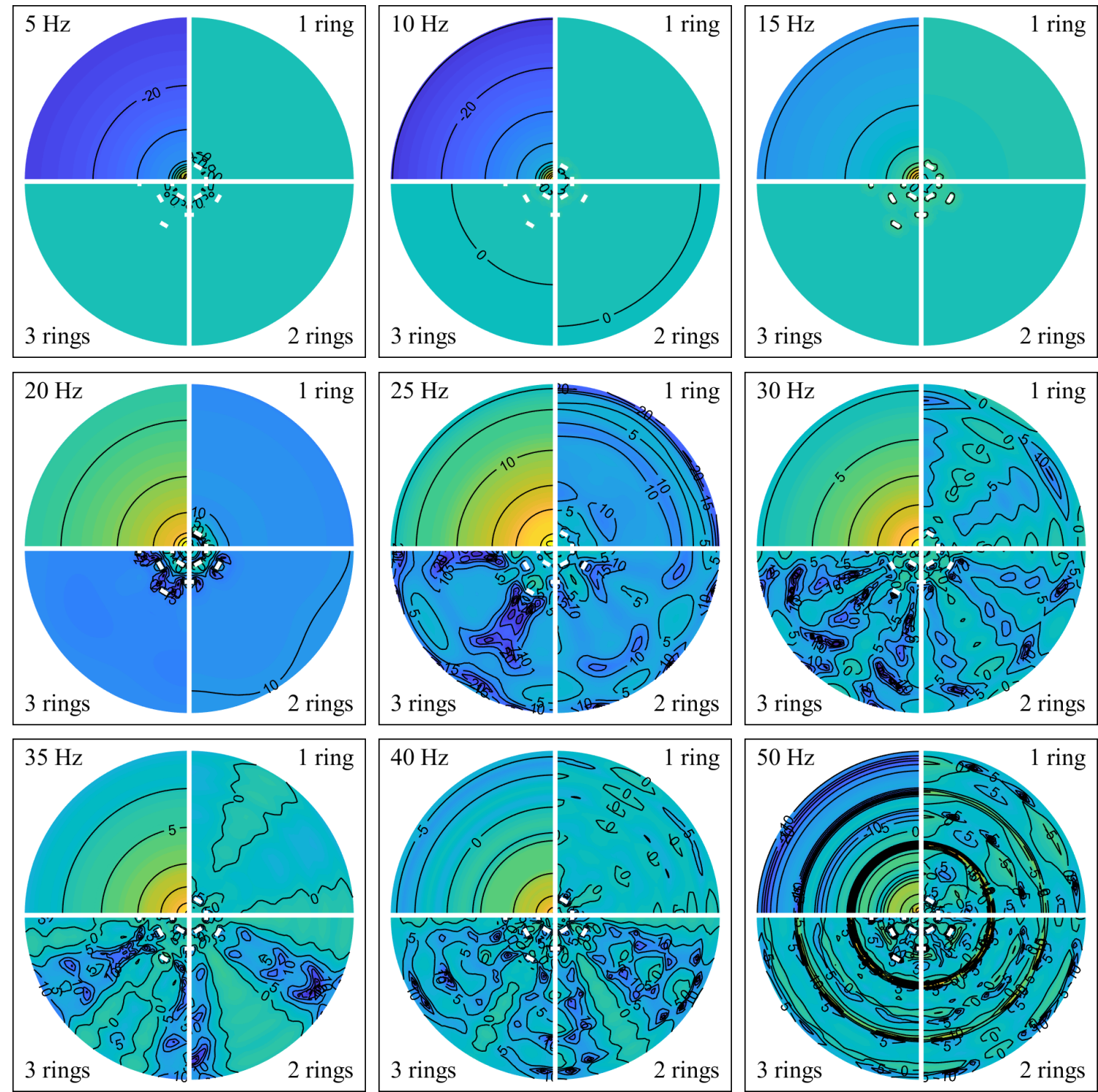

Figure 13: Contours of the reference vibration levels and insertion losses (in $\mathrm{dB}$ ) for Case 1.2b, "turned rings" with 1, 2 and 3 rings. Pale yellow/dark blue shades represent unfavourable/favourable values, respectively. 


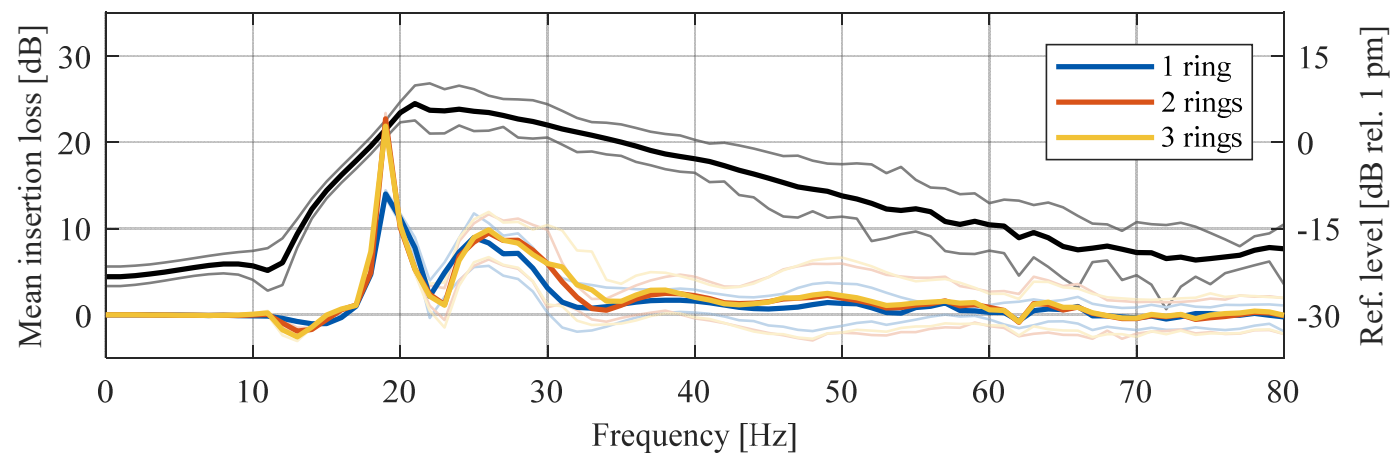

Figure 14: Mean insertion loss in $\mathrm{dB}$ for the donut-shaped zone between $20 \mathrm{~m}$ and $40 \mathrm{~m}$ away from the centre of the loaded area. Case 1.2c: "Linear arrays" with $1 \mathrm{~m}$ high blocks (inner circle) on soft dry sand over till. The black line shows the reference level of vibration. Thin lines show $10 \%$ and $90 \%$ quantiles.
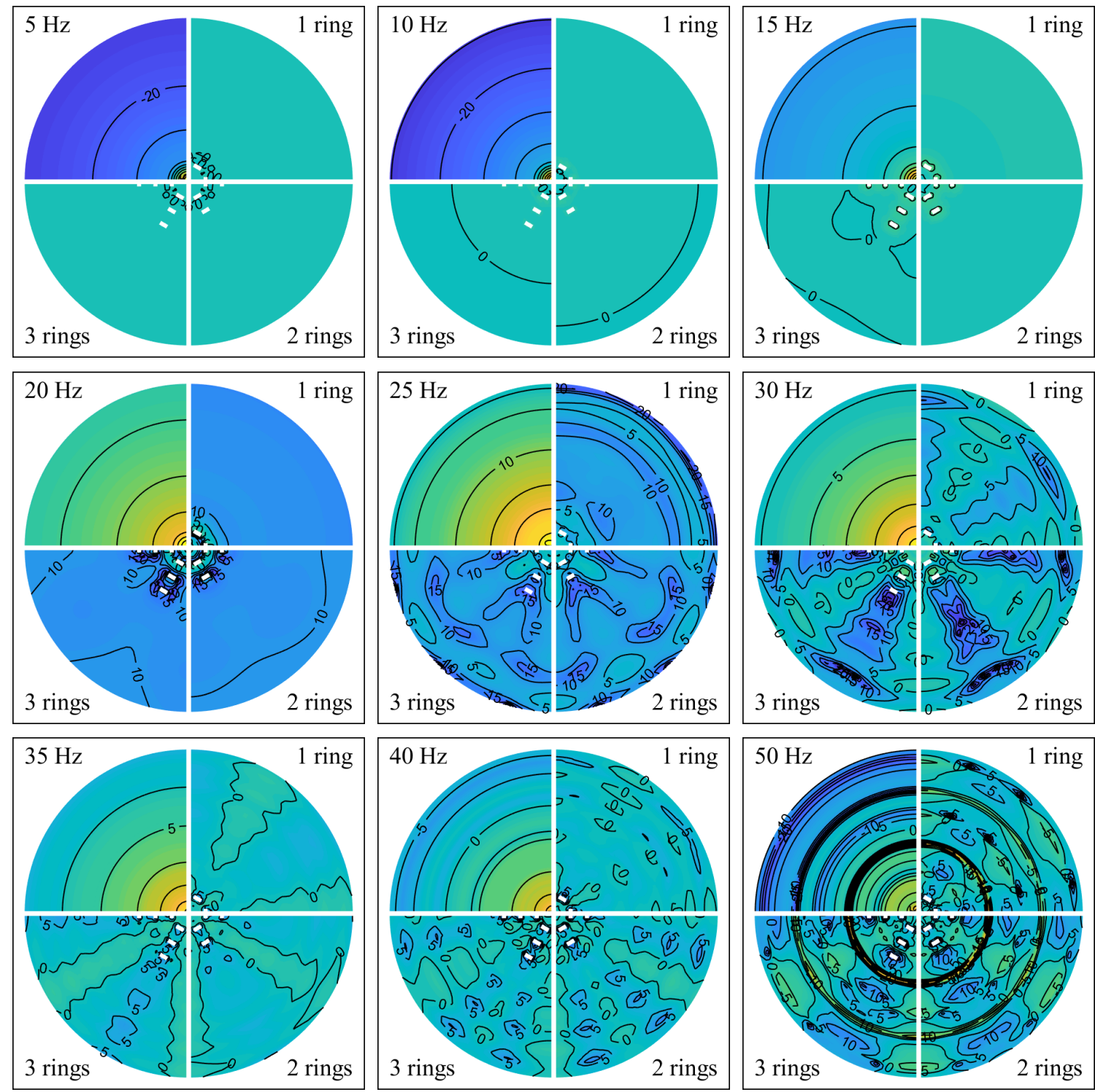

Figure 15: Contours of the reference vibration levels and insertion losses (in $\mathrm{dB}$ ) for Case 1.2c, "linear arrays" with 1, 2 and 3 rings. Pale yellow/dark blue shades represent unfavourable/favourable values, respectively. 


\subsection{Case 1.3: $3 \mathrm{~m}$ high blocks in three configurations}

Table 4 lists the resonance frequencies of the $3 \mathrm{~m}$ high blocks in Case 1.3. These are lower than those in Case 1.2 and even lower than those of Case 1.1. Of particular interest to the present problem, the resonance frequencies of the $3 \mathrm{~m}$ high blocks (for the heave and pitch modes) fall below $21 \mathrm{~Hz}$ where the RL of vibration peaks. Hence, it may be expected that the $3 \mathrm{~m}$ high block will not interact dynamically with the soil to the same extent as the smaller blocks.

\begin{tabular}{lllllll}
\hline & \multicolumn{2}{l}{ Blocks in Ring 1 } & \multicolumn{2}{l}{ Blocks in Ring 2 } & \multicolumn{2}{l}{ Blocks in Ring 3 } \\
\cline { 2 - 6 } & Heave & Pitch & Heave & Pitch & Heave & Pitch \\
\hline Case 1.3a & 17.11 & 4.185 & 19.79 & 5.539 & 23.25 & 7.047 \\
Case 1.3b & 17.11 & 4.185 & 17.09 & 5.111 & 17.09 & 4.181 \\
Case 1.3c & 17.11 & 4.185 & 17.09 & 4.181 & 17.09 & 4.181 \\
\hline
\end{tabular}

Table 4: Resonance frequencies (in Hz) of blocks in Case 1.3.

Figure 16 shows the mean values of the IL and RL in the shielded zone $(20 \mathrm{~m}$ to $40 \mathrm{~m}$ from the centre of the load) in Case 1.3a for the frequency range $0-80 \mathrm{~Hz}$ and for "Stonehenge" configurations with either 1, 2 or 3 rings. Figure 17 shows the RL (top left quadrants of the subplots) and IL (remaining quadrants of the subplots) on the ground surface at nine selected frequencies. Figure 18 and Figure 19 show similar results for Case 1.3b, the "turned rings", while Figure 20 and Figure 21 show the results for Case 1.3c, the "linear arrays".

Comparing Case 1.3 to Case 1.2, the main observation is that the $3 \mathrm{~m}$ high blocks perform poorly compared to the $2 \mathrm{~m}$ high blocks. It must be emphasized that this is an observation for the present configurations of the blocks and for the present stratification of the soil. However, it cannot be generalized, and in other situations, larger masses may be preferred. Also, increasing the mass by using higher density or increasing the footprint instead of the height may have a different influence on the result.

Apart from the lower IL compared to Case 1.2, the "Stonehenge" configuration with two or three rings (Figure 16 and Figure 17) performs significantly better than the "turned rings" and "linear arrays" (Figures 18 to 21) in the frequency range 25-30 Hz, whereas the opposite observation can be made in a narrow range near $16 \mathrm{~Hz}$. Further, at $25 \mathrm{~Hz}$ the "Stonehenge" configuration with three rings provide an almost axisymmetric IL distribution in the shielded zone, whereas the "turned rings" provide a radial (or ray-formed) pattern with very large IL in smaller zones. Finally, at $25 \mathrm{~Hz}$ the "linear array" with three rings provides very low IL. Generally, the addition of Ring 3 provides very little improvement in Case $1.3 \mathrm{c}$ with "linear arrays" of $3 \mathrm{~m}$ high blocks on the soft dry sand layer over the till half-space. 


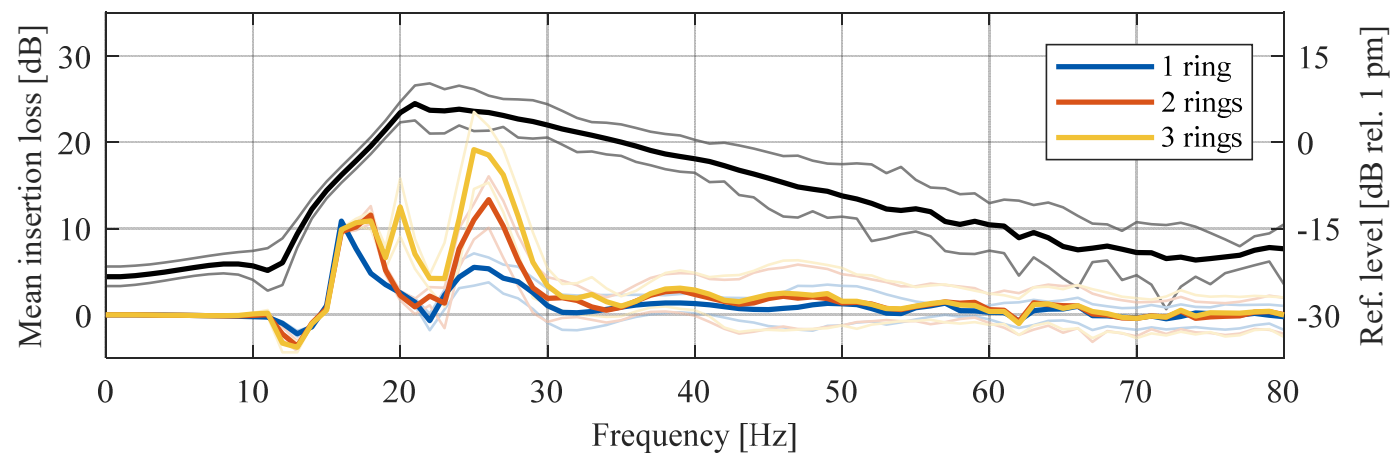

Figure 16: Mean insertion loss in $\mathrm{dB}$ for the donut-shaped zone between $20 \mathrm{~m}$ and $40 \mathrm{~m}$ away from the centre of the loaded area. Case 1.3a: "Stonehenge" with $3 \mathrm{~m}$ high blocks (inner circle) on soft dry sand over till. The black line shows the reference level of vibration. Thin lines show $10 \%$ and $90 \%$ quantiles.
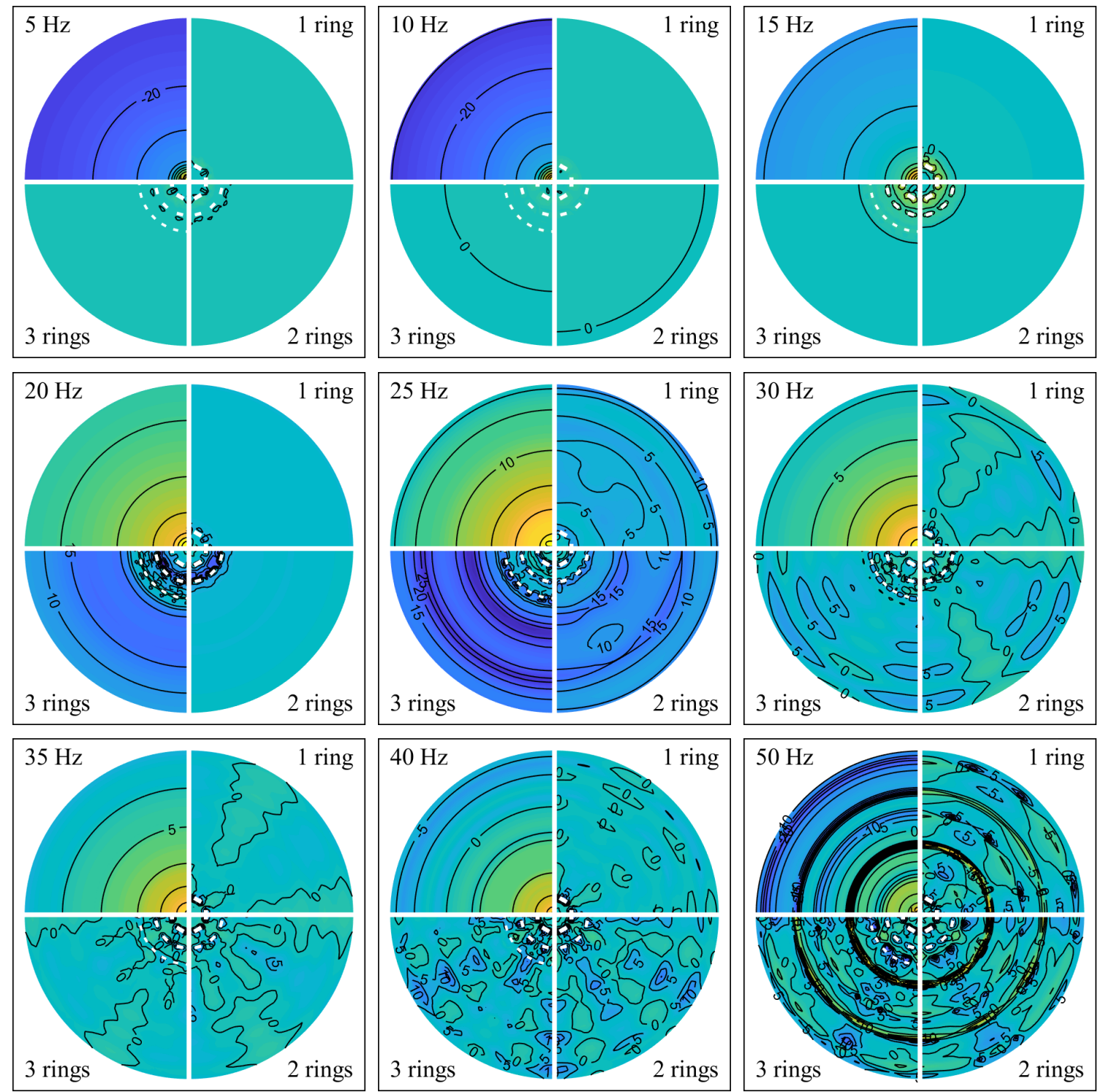

Figure 17: Contours of the reference vibration levels and insertion losses (in $\mathrm{dB}$ ) for Case 1.3a, "Stonehenge" with 1, 2 and 3 rings. Pale yellow/dark blue shades represent unfavourable/favourable values, respectively. 


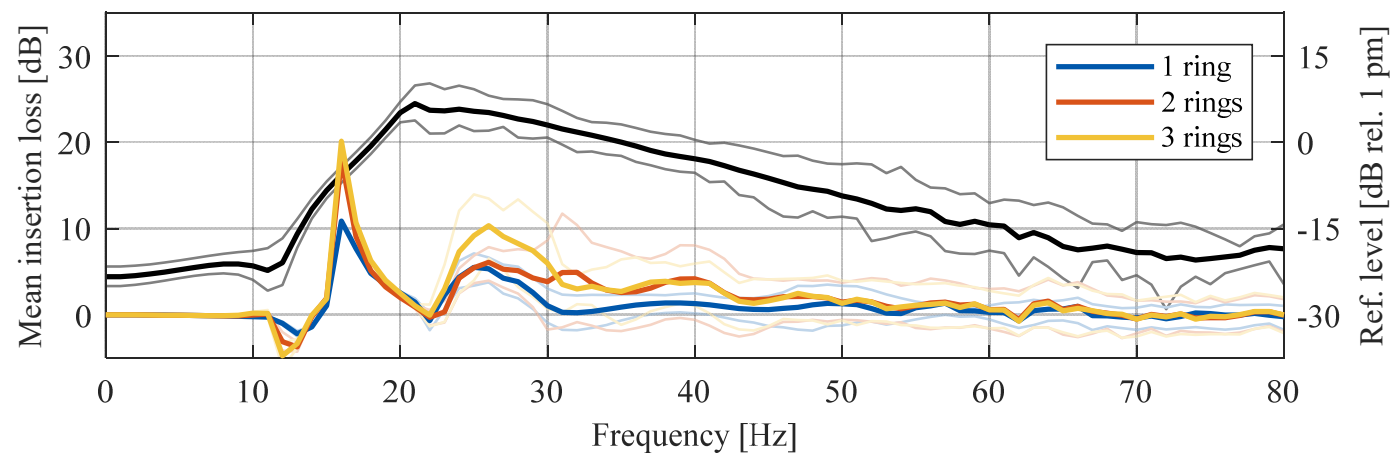

Figure 18: Mean insertion loss in $\mathrm{dB}$ for the donut-shaped zone between $20 \mathrm{~m}$ and $40 \mathrm{~m}$ away from the centre of the loaded area. Case 1.3b: "Turned rings" with $3 \mathrm{~m}$ high blocks (inner circle) on soft dry sand over till. The black line shows the reference level of vibration. Thin lines show $10 \%$ and $90 \%$ quantiles.
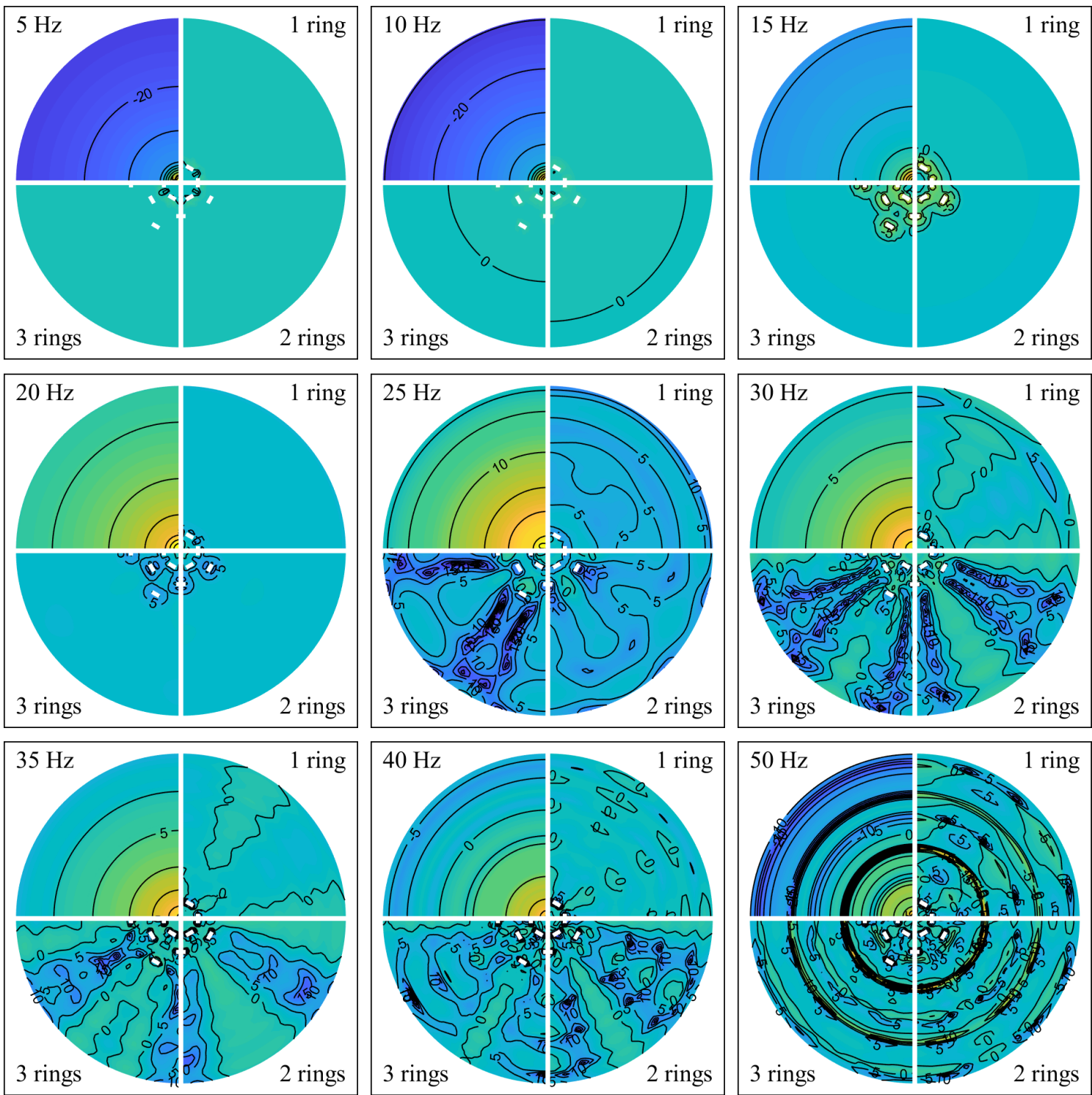

Figure 19: Contours of the reference vibration levels and insertion losses (in $\mathrm{dB}$ ) for Case 1.3b, "turned rings" with 1, 2 and 3 rings. Pale yellow/dark blue shades represent unfavourable/favourable values, respectively. 


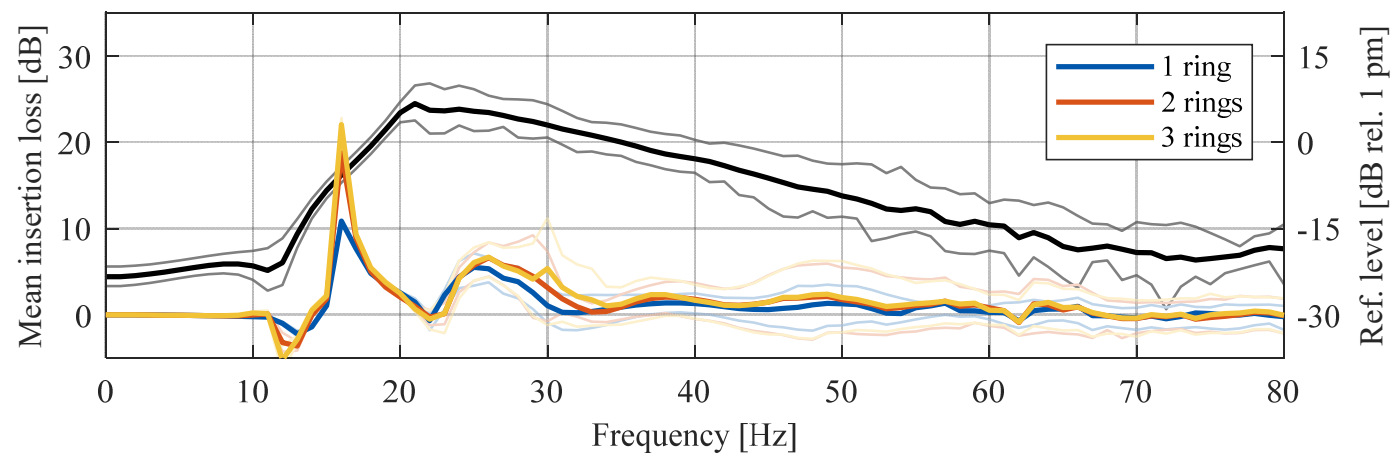

Figure 20: Mean insertion loss in $\mathrm{dB}$ for the donut-shaped zone between $20 \mathrm{~m}$ and $40 \mathrm{~m}$ away from the centre of the loaded area. Case 1.3c: "Linear arrays" with $3 \mathrm{~m}$ high blocks (inner circle) on soft dry sand over till. The black line shows the reference level of vibration. Thin lines show $10 \%$ and $90 \%$ quantiles.
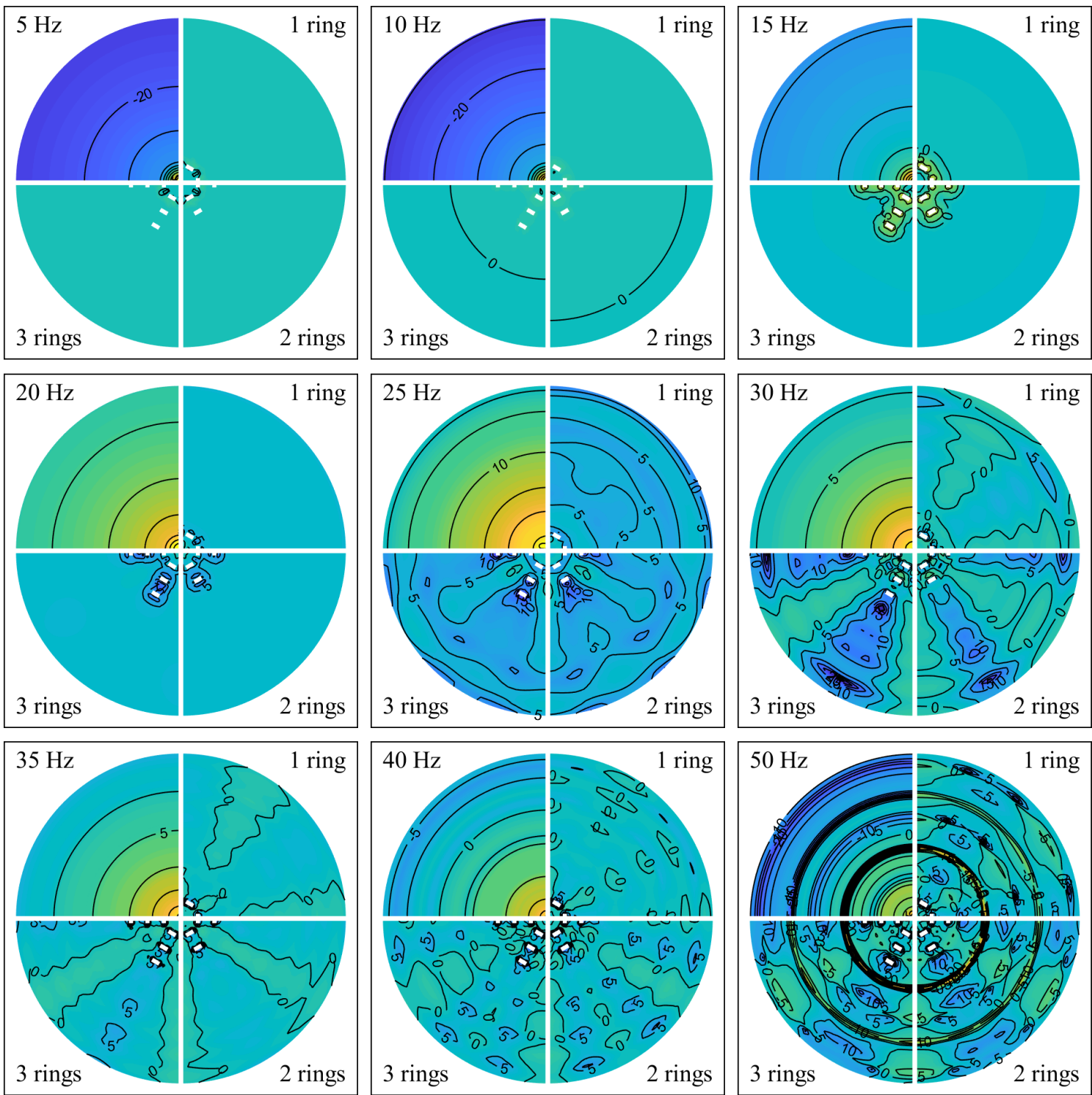

Figure 21: Contours of the reference vibration levels and insertion losses (in $\mathrm{dB}$ ) for Case 1.3c, "linear arrays" with 1, 2 and 3 rings. Pale yellow/dark blue shades represent unfavourable/favourable values, respectively. 


\section{CASE 2: A SOFT WET CLAY LAYER OVER A HALF-SPACE OF LIME}

The second case concerns a $5 \mathrm{~m}$ deep soft wet clay layer overlying a half-space of lime. Material properties for the two soil layers are listed in Table 5. The main difference compared to the previous case, i.e. Case 1, is the larger depth of the top layer combined with the slightly lower shear modulus. This provides a cut-on frequency of about $7 \mathrm{~Hz}$ in Case 2, whereas the cut-on frequency was around $12.5 \mathrm{~Hz}$ in Case 1 . Hence, it can be expected that higher mitigation effect can be obtained by using higher blocks with lower resonance frequencies in this case, compared to Case 1 . Hence, in this section, only results for $3 \mathrm{~m}$ high blocks will be discussed. The resonance frequencies for these blocks are given in Table 6 .

\begin{tabular}{llllll}
\hline $\begin{array}{l}\text { Soil layer } \\
\text { (from top) }\end{array}$ & $\begin{array}{l}\text { Shear modulus } \\
G[\mathrm{MPa}]\end{array}$ & $\begin{array}{l}\text { Poisson's ratio } \\
v[-]\end{array}$ & $\begin{array}{l}\text { Mass density } \\
\rho\left[\mathrm{kg} / \mathrm{m}^{3}\right]\end{array}$ & $\begin{array}{l}\text { Loss factor } \\
\eta[\%]\end{array}$ & $\begin{array}{l}\text { Thickness } \\
h[\mathrm{~m}]\end{array}$ \\
\hline Sand, soft, $d r y$ & 30.03 & 0.4942 & 1694 & 4.50 & 5.0 \\
Till (half-space) & 4300 & 0.3500 & 2100 & 2.00 & $\infty$ \\
\hline
\end{tabular}

Table 5: Soil properties for Case 2.

\begin{tabular}{lllllll}
\hline & \multicolumn{2}{l}{ Blocks in Ring 1 } & \multicolumn{2}{l}{ Blocks in Ring 2 } & \multicolumn{2}{l}{ Blocks in Ring 3 } \\
\cline { 2 - 7 } & Heave & Pitch & Heave & Pitch & Heave & Pitch \\
\hline Case 2a & 17.85 & 4.420 & 20.72 & 5.854 & 24.41 & 7.451 \\
Case 2b & 17.84 & 4.420 & 17.81 & 5.391 & 17.80 & 4.415 \\
Case 2c & 17.84 & 4.420 & 17.81 & 4.415 & 17.80 & 4.415 \\
\hline
\end{tabular}

Table 6: Resonance frequencies of blocks in Case 2.

Figure 22 shows the mean values of the IL and RL in the shielded zone $(20 \mathrm{~m}$ to $40 \mathrm{~m}$ from the centre of the load) in Case $2 \mathrm{a}$ for the frequency range $0-80 \mathrm{~Hz}$ and for "Stonehenge" configurations with either 1, 2 or 3 rings. Figure 23 shows the RL (top left quadrants of the subplots) and IL (remaining quadrants of the subplots) on the ground surface at nine selected frequencies. Figure 24 and Figure 25 show similar results for Case 2b, the "turned rings", while Figure 26 and Figure 27 show the results for Case 2c, the "linear arrays".

Compared to Case 1, the RL of vibration is lower at frequencies below the cut-on frequency. This is caused by the higher stiffness of the lime half-space in Case 2 compared to that of the till half-space in Case 1. However, the peak RL is slightly higher in Case 2 compared to the peak RL in Case 1, since the clay is slightly softer than the sand.

For the soil profile considered in Case 2, the various block array configurations mainly provide mitigation of ground vibrations in the frequency range 12-27 Hz. The "turned rings" have a good performance around $12-13 \mathrm{~Hz}$ and again near $20 \mathrm{~Hz}$. However, outside these narrow peaks, the IL is low. The "linear arrays" have a similar performance, but the IL in the intermediate range 13-18 Hz is better than for the "turned rings". As can be seen from Figure 25, there is a clear radial pattern in the IL at $15 \mathrm{~Hz}$ for both these configurations.

The "Stonehenge" configuration is about $5 \mathrm{~dB}$ less effective than the other configurations at frequencies near $12-13 \mathrm{~Hz}$. On the contrary, it provides $10 \mathrm{~dB}$ higher IL at frequencies around $25 \mathrm{~Hz}$ - however only when all three rings are present. A possible explanation to this is the somewhat higher resonance frequency of the heave mode for the smaller masses in Ring 3 of the "Stonehenge" configuration. Whereas the resonance frequency for the larger blocks in the inner ring, and in all rings of Cases $2 \mathrm{~b}$ and $2 \mathrm{c}$, are below $20 \mathrm{~Hz}$, the resonance frequency of the heave mode related to the smaller blocks in Ring 3 of Case $2 \mathrm{a}$ is above $24 \mathrm{~Hz}$. Similarly, it can be seen that the "Stonehenge" with two rings provides slightly higher TL for frequencies just above $20 \mathrm{~Hz}$, but lower IL at $20 \mathrm{~Hz}$ than the array with only one ring. 


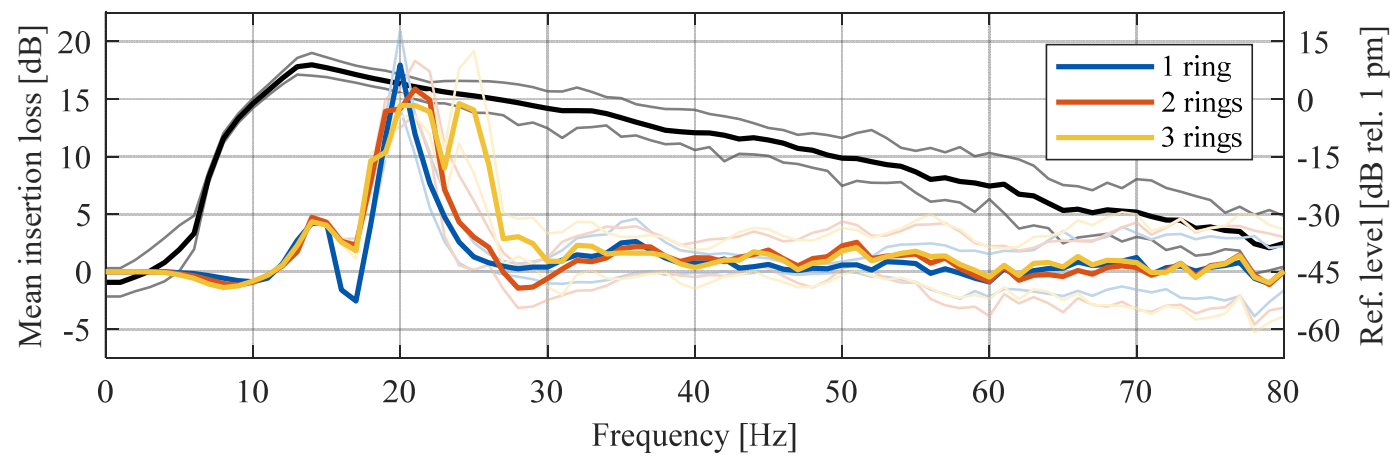

Figure 22: Mean insertion loss in dB for the donut-shaped zone between $20 \mathrm{~m}$ and $40 \mathrm{~m}$ away from the centre of the loaded area. Case 2a: "Stonehenge" with 3 m high blocks (inner circle) on soft wet clay over lime.

The black line shows the reference level of vibration. Thin lines show $10 \%$ and $90 \%$ quantiles.
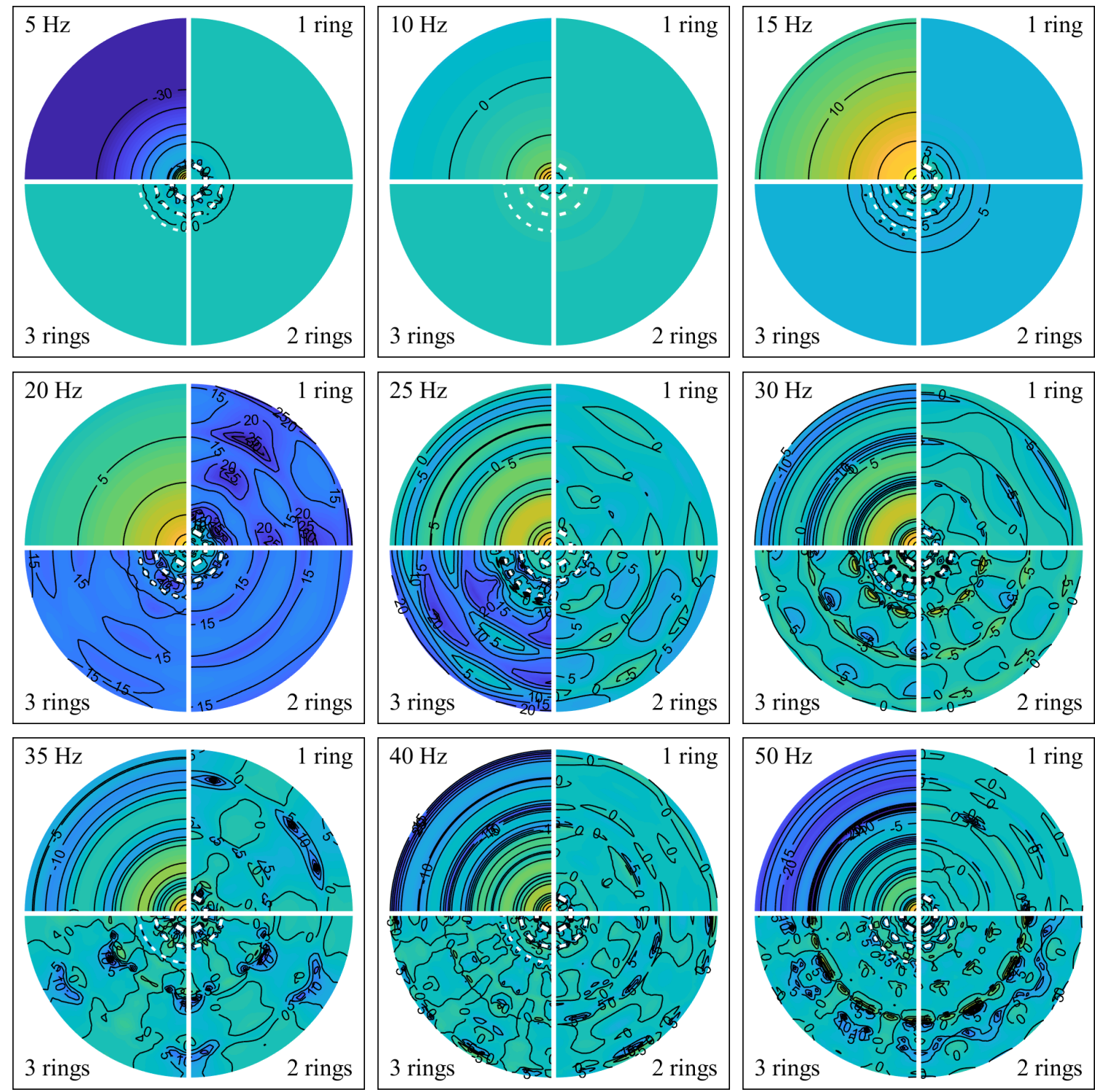

Figure 23: Contours of the reference vibration levels and insertion losses (in $\mathrm{dB}$ ) for Case 2a, "Stonehenge" with 1, 2 and 3 rings. Pale yellow/dark blue shades represent unfavourable/favourable values, respectively. 


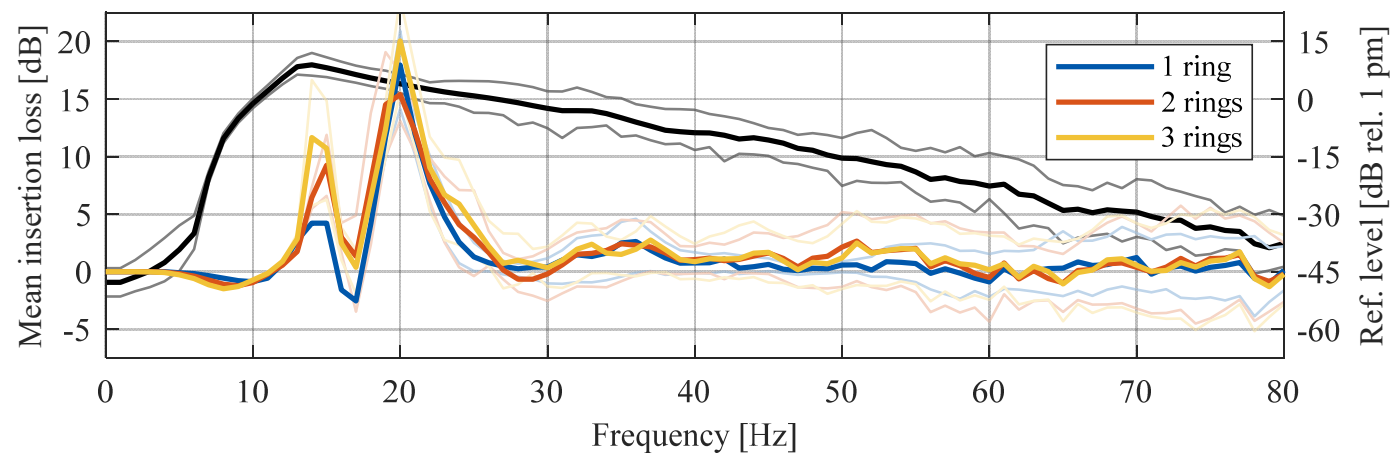

Figure 24: Mean insertion loss in $\mathrm{dB}$ for the donut-shaped zone between $20 \mathrm{~m}$ and $40 \mathrm{~m}$ away from the centre of the loaded area. Case 2b: "Turned rings" with $3 \mathrm{~m}$ high blocks (inner circle) on soft wet clay over lime.

The black line shows the reference level of vibration. Thin lines show $10 \%$ and $90 \%$ quantiles.
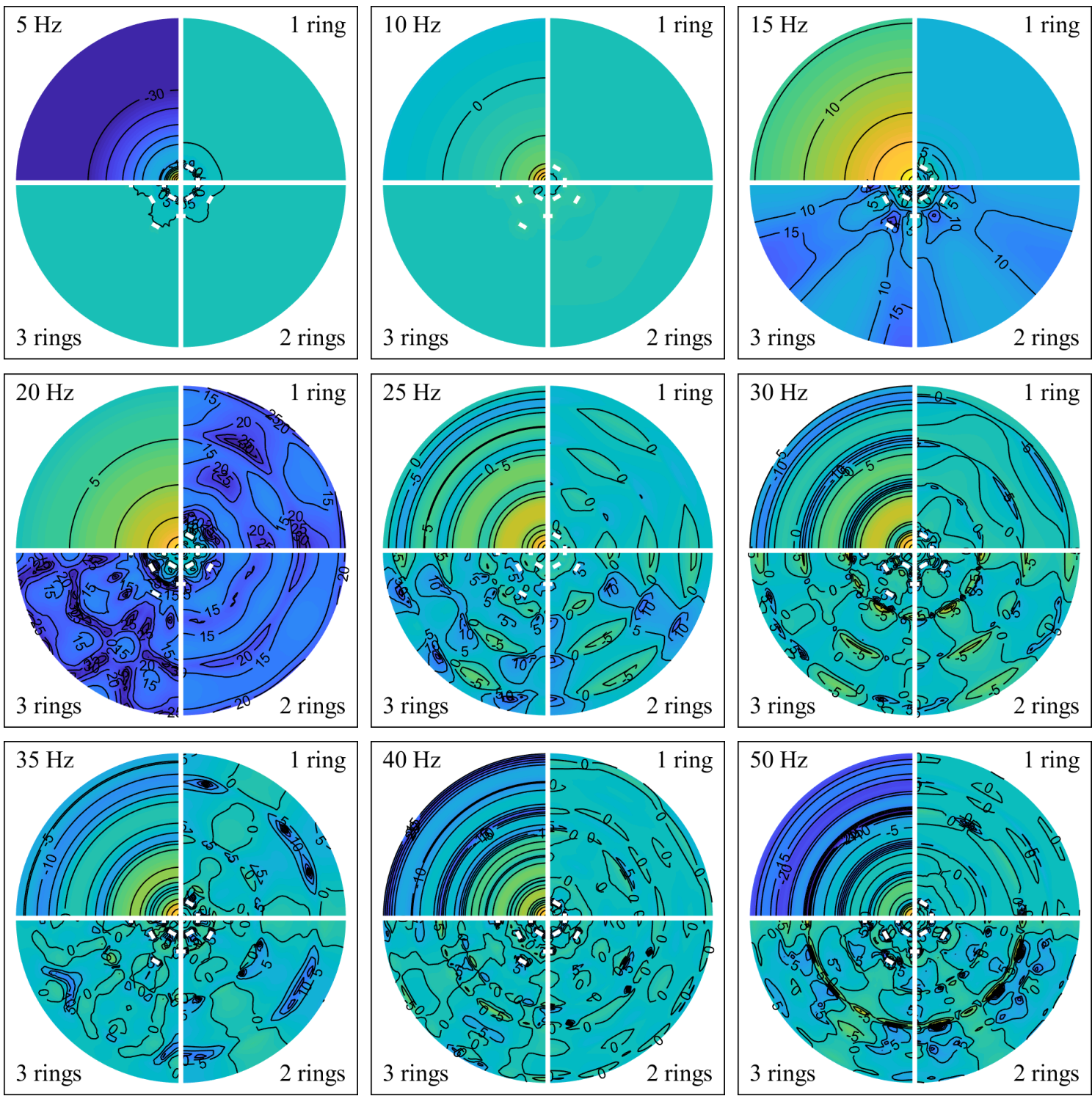

Figure 25: Contours of the reference vibration levels and insertion losses (in $\mathrm{dB}$ ) for Case $2 \mathrm{~b}$, "turned rings" with 1, 2 and 3 rings. Pale yellow/dark blue shades represent unfavourable/favourable values, respectively. 


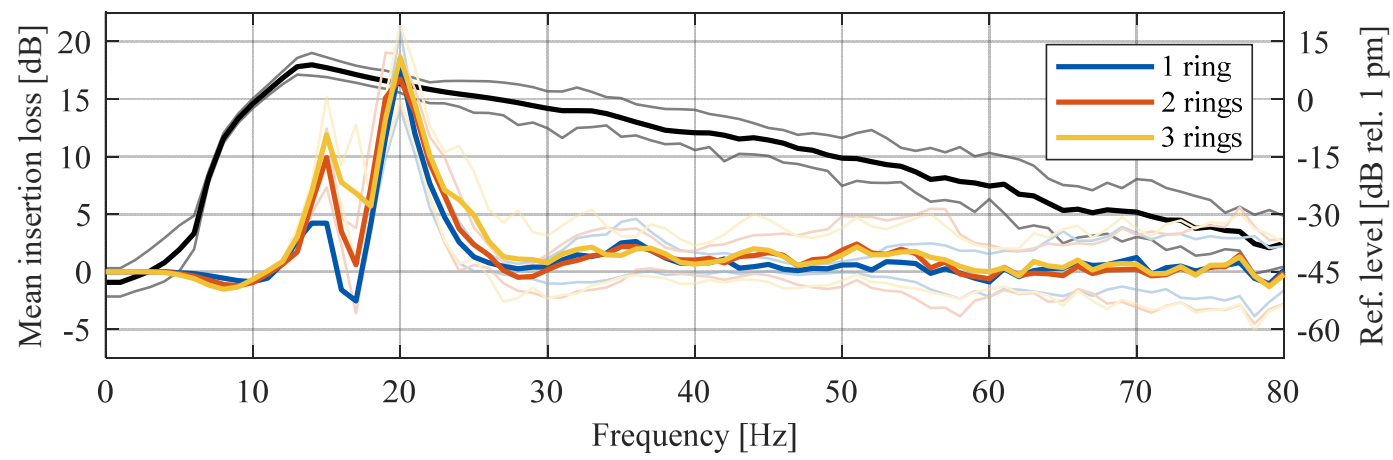

Figure 26: Mean insertion loss in $\mathrm{dB}$ for the donut-shaped zone between $20 \mathrm{~m}$ and $40 \mathrm{~m}$ away from the centre of the loaded area. Case 2c: "Linear arrays" with $3 \mathrm{~m}$ high blocks (inner circle) on soft wet clay over lime. The black line shows the reference level of vibration. Thin lines show $10 \%$ and $90 \%$ quantiles.
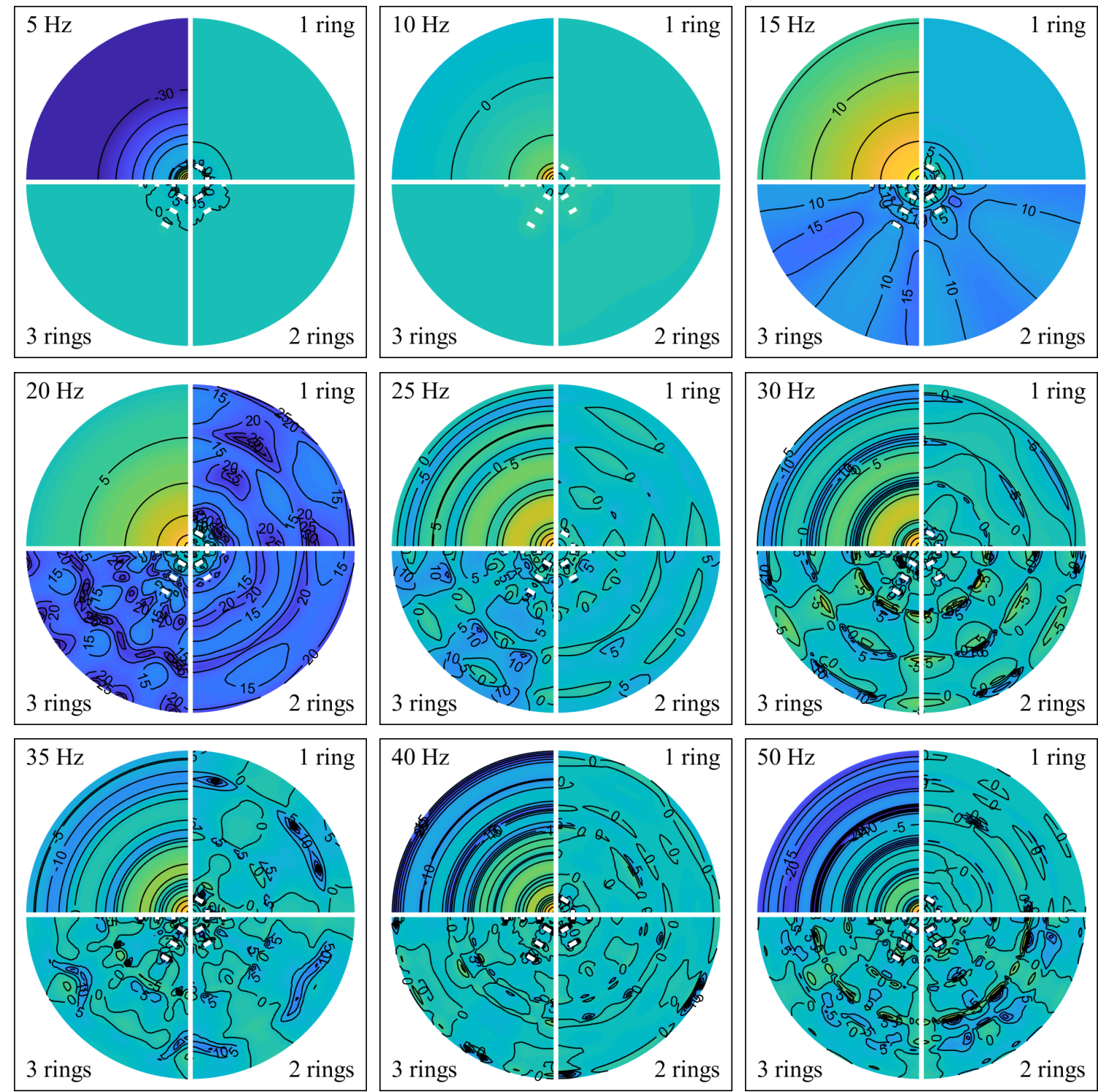

Figure 27: Contours of the reference vibration levels and insertion losses (in $\mathrm{dB}$ ) for Case 2c, "linear arrays" with 1, 2 and 3 rings. Pale yellow/dark blue shades represent unfavourable/favourable values, respectively. 


\section{CONCLUSIONS}

Circular arrays of rigid blocks interacting dynamically with a horizontally layered linear viscoelastic half-space have been analysed. Especially, the mitigation efficiency of such arrays placed around a load acting on the ground surface has been quantified. Two different cases have been considered: Case 1) a soft dry sand layer over a till half-space; Case 2) a soft wet clay layer over a lime half-space. For each case, three different configurations of the circular block arrays have been examined: a) a "Stonehenge" configuration with up to three concentric rings of blocks; b) a "turned rings" configuration with the middle ring turned relatively to the inner and outer ring; c) a "linear array" configuration similar to the "turned rings", but with all rings oriented in the same way to obtain six rays of linear block arrays.

For Case 1, blocks of different heights have been considered. Only $3 \mathrm{~m}$ high blocks have been analysed for Case 2 . In all the analyses, the frequency range $0-80 \mathrm{~Hz}$ has been considered due to its relevance to annoyance caused by whole-body vibration as well as structural damage caused by resonance in the fundamental modes of a building. Results have been presented in terms of the insertion loss that occurs after insertion of one, two or three rings of blocks in each considered combination of soil and array configuration. The mean value of the insertion loss has been calculated for a shielded zone, $20 \mathrm{~m}$ to $40 \mathrm{~m}$ away from the centre of the circular loaded area. The main conclusions of the paper are as follows:

- Circular arrays of blocks can have a significant mitigation effect. Insertion losses up to about $20 \mathrm{~dB}$ have been observed at frequencies that are relevant to whole-body vibration as well as the first modes of resonance in buildings.

- In the cases considered in the paper, the circular block arrays have been found to be particularly effective in the frequency range between the cut-on frequency for wave propagation in the soft topsoil layer and up to about $30-40 \mathrm{~Hz}$. This is an important finding, since this is typically the frequency range in which problems with ground vibrations can arise due to the frequency contents of sources - e.g., traffic or pile driving — combined with the ability of the ground to transfer vibrations at different frequencies.

- The height of the blocks can be adjusted to change the resonance frequencies of the heave and pitch mode. This may be useful in order to calibrate the blocks for optimal performance of the circular arrays in terms of ground vibration mitigation.

- In many cases, the "Stonehenge" configurations have been found to provide higher insertion losses that the two other configurations of the block arrays. This suggests that combination of blocks with different sizes can be a good alternative to using blocks of equal size.

\section{ACKNOWLEDGMENTS}

The third author gratefully acknowledge the financial support from the Swedish Governmental Agency for Innovation Systems (Vinnova), grant ref.no. 2018-04159, as well as from the City of Helsingborg through the call "Plattformen". 


\section{REFERENCES}

[1] L. Andersen and S. R. K. Nielsen, "Reduction of ground vibration by means of barriers or soil improvement along a railway track," Soil Dyn. Earthq. Eng., vol. 25, no. 7-10, pp. 701-716, Aug. 2005.

[2] D. J. Thompson et al., "Reducing railway-induced ground-borne vibration by using open trenches and soft-filled barriers," Soil Dyn. Earthq. Eng., vol. 88, pp. 45-59, Sep. 2016.

[3] A. Dijckmans et al., "Mitigation of railway induced ground vibration by heavy masses next to the track," Soil Dyn. Earthq. Eng., vol. 75, pp. 158-170, 2015.

[4] L. Andersen and A. H. Augustesen, "Mitigation of traffic-induced ground vibration by inclined wave barriers - A three-dimensional numerical analysis," in 16th International Congress on Sound and Vibration 2009, ICSV 2009, 2009, vol. 4.

[5] L. Andersen and M. Liingaard, "Vibration screening with sheet pile walls," in Environmental Vibrations: Prediction, Monitoring, Mitigation and Evaluation (ISEV 2005), 2005, pp. 429-437.

[6] G. B. Warburton, J. D. Richardson, and J. J. Webster, "Forced Vibrations of Two Masses on an Elastic Half Space,” J. Appl. Mech., vol. 38, no. 1, pp. 148-156, 1971.

[7] G. B. Warburton, H. D. Richardson, and J. J. Webster, "Harmonic response of masses on an elastic half-space," J. Eng. Ind. Trans. ASME, vol. 75, pp. 158-170, 1972.

[8] A. T. Peplow, C. J. C. Jones, and M. Petyt, "Surface vibration propagation over a layered elastic half-space with an inclusion," Appl. Acoust., 1999.

[9] H. Masoumi, A. Van Leuven, and S. Urbaniak, "Mitigation of train induced vibrations by wave impeding blocks: numerical prediction and experimental validation," in EURODYN 2014, 2014, no. July, pp. 863-870.

[10] D. J. Mead, "Free wave propagation in periodically supported, infinite beams," J. Sound Vib., vol. 11, no. 2, pp. 181-197, 1970.

[11] C. van Hoorickx, O. Sigmund, M. Schevenels, B. S. Lazarov, and G. Lombaert, "Topology optimization of two-dimensional elastic wave barriers," J. Sound Vib., vol. 376, pp. 95-111, 2016.

[12] P. Persson, K. Persson, and G. Sandberg, "Reduction in ground vibrations by using shaped landscapes," Soil Dyn. Earthq. Eng., vol. 60, pp. 31-43, 2014.

[13] L. V. Andersen, "Using periodicity to mitigate ground vibration," in COMPDYN 2015 5th ECCOMAS Thematic Conference on Computational Methods in Structural Dynamics and Earthquake Engineering, 2015.

[14] L. V. Andersen, P. Bucinskas, P. Persson, M. Muresan, L.-I. Muresan, and I.-O. Paven, "Mitigating ground vibration by periodic inclusions and surface structures," in Proceedings of the INTER-NOISE 2016 - 45th International Congress and Exposition on Noise Control Engineering: Towards a Quieter Future, 2016, pp. 7469-7480.

[15] L. V. Andersen, A. Peplow, P. Bucinskas, P. Persson, and K. Persson, "Variation in models for simple dynamic structure-soil-structure interaction problems," in Procedia Engineering, 2017, vol. 199.

[16] L. V. Andersen, A. Peplow, and P. Bucinskas, "Efficiency of nearly periodic structures for mitigation of ground vibration," in Proceedings of the 6th International Conference 
on Computational Methods in Structural Dynamics and Earthquake Engineering (COMPDYN 2015), 2017, pp. 537-558.

[17] A. Peplow, L. Andersen, and P. Bucinskas, "Variations within simple models for structure-soil interaction," in 24th International Congress on Sound and Vibration, ICSV 2017, 2017.

[18] A. T. Peplow, L. V. Andersen, and P. Bucinskas, "Environmental vibration reduction utilizing an array of mass scatterers," in Procedia Engineering, 2017, vol. 199.

[19] W. T. Thomson, "Transmission of elastic waves through a stratified solid medium," $J$. Appl. Phys., vol. 21, no. 2, pp. 89-93, 1950.

[20] N. A. Haskell, "The dispersion of surface waves on multilayered media," Bull. Seismol. Soc. Am., vol. 43, no. 1, pp. 17-34, Jan. 1953.

[21] L. Andersen and J. Clausen, "Impedance of surface footings on layered ground," Comput. Struct., vol. 86, no. 1-2, pp. 72-87, 2008. 